The dynamic relationship between valuing diversity and intergroup contact: is valuing diversity a precursor to contact and mediator of diverse contact effects?

Keywords: intergroup contact, diversity beliefs, multiculturalism, prejudice, social integration

Data availability statement: The data for Studies 1 and 2, and the analysis code for all three studies are available at https://osf.io/sbpxj/?view_only=7d652e89096d4c39b8ca5de893ac384a. 
The dynamic relationship between valuing diversity and intergroup contact: is valuing diversity a precursor to contact and mediator of diverse contact

\title{
effects?
}

\begin{abstract}
Valuing diversity and intergroup contact predict less prejudice and discrimination, yet their relationship deserves closer attention. The evidence suggests that valuing diversity and (interest in) intergroup contact are associated, but the directionality is not clear, and it has not been tested whether the established effects of contact come about through changes in valuing diversity. We address this in three studies. In Study $1(N=211)$, using longitudinal survey data, both positive and negative contact affected the value placed on diversity over time, while valuing diversity did not significantly predict the frequency of future contact. Studies $2(N=224)$ and $3(N=2,618)$ consequently considered valuing diversity as a mediator and showed that it mediates the relationships of intergroup contact with prejudice, behavioral intentions, and policy support. Our results increase the understanding of pathways from intergroup contact to intergroup relations and offer a lever that contact interventions can target.
\end{abstract}

Keywords: Intergroup contact, diversity beliefs, multiculturalism, prejudice, social integration 


\section{The dynamic relationship between valuing diversity and intergroup contact: is valuing diversity a precursor to contact and mediator of diverse contact effects?}

Prejudice, discrimination and inequality persist as Western societies are becoming more diverse (Vertovec, 2007). In fact, they may have become more visible as part of a "hate speech epidemic" (Bilewicz \& Soral, 2020). Therefore, the question of how to develop more positive intergroup relations has continued to be a focus for social psychologists. Two primary fields of research have emerged, intergroup contact and diversity beliefs, both of which have yielded valuable insights. In this paper, we offer one of the first systematic connections between them. We provide the first longitudinal evidence regarding the relationships between both positive and negative intergroup contact and valuing diversity over time, and subsequently show that valuing diversity can help explain the pathways from intergroup contact to both cognitive and affective prejudice and behavioral intentions. We also suggest that promoting positive intergroup contact might be a way to increase the valuing of diversity that eschews the risks associated with other approaches.

\section{The importance of valuing diversity}

The question of how to deal with diversity has been debated over decades, particularly concerning whether diversity is to be recognized and valued (Leslie et al., 2020). At the one end, color-blind approaches suggest that diversity is best ignored and the focus placed on a unifying identity (Myers, 2019; Schlesinger, 1998), while at the other, multiculturalism calls for the valuing of diversity and a maintenance of cultural differences (Berry, 2016; Fowers \& Richardson, 1996). Despite the pronouncements by prominent political leaders that multiculturalism has failed and the decline in public support for the concept (Vertovec \& Wessendorf, 2010), the evidence clearly favors 
approaches that recognize and value diversity: A recent meta-analysis of 167

independent samples showed that an endorsement of multiculturalism is associated with less prejudice and discrimination, and greater support for pro-diversity policies than an endorsement of color-blindness (Leslie et al., 2020), which is in line with Plaut's et al. (2018) literature review that concluded that multiculturalism is more likely to contribute to positive interracial interactions.

Nevertheless, while an endorsement of multiculturalism is beneficial, attempts to promote it can backfire if they create identity threat on the part of majority-group members. For instance, multiculturalism is associated with a sense of exclusion among White US Americans (Plaut et al., 2011) and multiculturalism primes have been shown to lead to a greater endorsement of conservative political beliefs and greater warmth towards Donald Trump (Osborn et al., 2019). However, a focus on polyculturalism, a derivation of multiculturalism that adds a focus on continuous exchange and interaction between cultures, attenuated the backlash in Osborn et al. (2019) and has been associated with greater creativity (Cho et al., 2018) and interest in intergroup contact and support for equality (Rosenthal \& Levy, 2012, 2016). Additionally, it has been shown that an endorsement of multiculturalism is associated with greater essentialism, i.e. the notion that group-differences are 'valid, biologically based and immutable' (Wilton et al., 2019). Therefore, the question of how valuing diversity can be developed in a way that does not raise threat or promote essentialism deserves attention. In line with the promising findings from polyculturalism research, we consider here whether intergroup contact offers such a way.

\section{The promise of intergroup contact}

Intergroup contact has been described as one of the most successful ideas in social psychology (Dovidio et al., 2003). In any case, the "contact hypothesis", which states that contact between members of different groups reduces prejudice, has proved 
to be one of the most replicable. The largest meta-analysis to date found a negative association between contact and prejudice in $94 \%$ of the 713 samples considered (Pettigrew \& Tropp, 2006). This has enabled the design of successful prejudicereduction interventions in the field (Lemmer \& Wagner, 2015).

The positive effects of intergroup contact hold across different types of prejudice, to different extents: Tropp and Pettigrew (2005) suggested a distinction into affective factors (primarily emotions) and cognitive factors (stereotypes and beliefs), and found that positive contact shapes both dimensions, with significantly stronger effects on affective prejudice. Additionally, positive intergroup contact has been shown to be associated with greater intentions to help outgroup members (Corrigan et al., 2002; Johnston \& Glasford, 2018), to challenge exclusion (Abbott \& Cameron, 2014; Dessel et al., 2017) and to support policies that benefit disadvantaged groups (Selvanathan et al., 2017), even though these effects are less universal and less wellunderstood than those on prejudice. While one might expect that reductions in prejudice at least predict reductions in discriminatory behaviors, this relationship has been shown to be relatively weak: a meta-analysis of 60 studies estimated a correlation of just .29 (Schütz \& Six, 1996). Thus, changes in prejudice and in behavior need to be considered separately in research on the effects of intergroup contact, so that we will consider both types of outcomes in assessing the mediational role of valuing diversity.

\section{Predictors of intergroup contact}

Given the potential of (positive) intergroup contact to improve intergroup relations, the importance of understanding its antecedents has been increasingly recognized, especially given that individuals often avoid and rarely seek contact (Dixon \& Durrheim, 2003; Paolini et al., 2018). Predictors of avoidance are relatively wellestablished: intergroup anxiety (reviewed in Paolini et al., 2018), past experiences of negative contact (Meleady \& Forder, 2019), an expectation of negative outcomes (Plant 
et al., 2008), and ideological commitments (Dhont et al., 2014) all play a part.

Predictors of approach, on the other hand, have been studied less, even though they might aid the design of interventions that overcome the widespread avoidance (Paolini et al., 2018). Some research has shown that expansionary approaches to situations, be they endeavor-oriented personality traits (Stürmer et al., 2013) or experimentallyinduced self-expansion orientation (Dys-Steenbergen et al., 2016), predict greater openness to intergroup contact. Relatedly, research has suggested that placing a value on diversity increases individuals' desire to engage in contact.

\section{Valuing diversity as a predictor of contact}

Several studies have associated valuing diversity with intergroup contact, for instance through the observation of naturally occurring dyads, where members of diverse dyads held more favorable views of diversity (Bahns, 2017; Bahns et al., 2015). Directionally, it has been shown that valuing diversity predicts greater interest in contact, at least for majority group members (Tropp \& Bianchi, 2006; Yogeeswaran et al., 2020). Similarly, in an experimental study among primary school children, exposure to a storybook promoting multiculturalism led to a (short-term) reduction in ethnic selfsegregation during lunchtime, though the effect disappeared within 48 hours (McKeown

et al., 2017). Similarly, among adults valuing diversity has been shown to be associated with lower intentions to to avoid exposure to and interactions with outgroup members (Kauff \& Wagner, 2012, Study 1). However, there is little research to date that links diversity beliefs to the incidence of intergroup contact.

\section{A dynamic perspective}

One of the most potent predictors of intergroup contact is past intergroup contact (Binder et al., 2009; Braddock \& McPartland, 1989; Emerson et al., 2002), which hints at the possibility for the emergence of 'virtuous cycles' in which some outcomes of positive contact become precursors of future contact (Paolini et al., 2018). Here we 
explored whether valuing diversity can play such a role in a virtuous cycle - that is, whether valuing diversity leads to more contact (as indicated by the studies cited above), and whether that contact further increases the valuing of diversity. Crosssectional observational data clearly does not allow for the testing of these relationships. As far as we are aware, only one study has tested the link between intergroup contact and diversity beliefs over time. In their sample of US college students, Harper and Yeung (2013) found that for White students, the frequency of social interactions with students of a different race or ethnicity over the course of two years predicted a greater valuing of diversity in their junior year. However, they only controlled for valuing diversity at baseline and did not include an autoregressive path for contact. This weakens the longitudinal approach substantially as it is not clear whether an earlier level of contact predicted valuing diversity, or whether the frequency of contact changed alongside changes in valuing diversity. Furthermore, they did not consider the valence of contact, implicitly following the majority of contact research in conflating contact with positive contact.

\section{Not all contact is positive}

The overwhelming focus on positive contact in the literature, while understable given the desire to find solutions to reduce prejudice, has come to be criticized over the past decade, particularly after it was suggested that negative contact is a stronger predictor of prejudice than positive contact is (Barlow et al., 2012). This asymmetry has not replicated consistently: while some later studies also found negative contact to be a stronger predictor of intergroup outcomes (Graf et al., 2014; Hayward et al., 2017; Landmann et al., 2019), others found positive contact to be more influential (Bagci \& Turnuklu, 2018; Meleady \& Forder, 2019; Visintin et al., 2017; Wölfer et al., 2017). A recent meta-analysis suggested that this depends on the status of the outgroups under consideration: contact that is in line with expectations (i.e. negative contact for negative 
outgroups, positive contact for positive outgroups) was found to have the strongest effect (Paolini \& McIntyre, 2019). Another review suggested that the relative effects depend on the outcome under consideration: negative contact enhanced negative emotions while positive contact enhanced positive emotions ("affect matching", Barlow et al., 2019). In any case, both positive and negative contact typically have substantial and distinct effects on intergroup outcomes, but there is no evidence regarding the links between negative contact and diversity beliefs to date. Therefore, we will consider positive and negative contact separately and see how they influence diversity beliefs and/or are influenced by them.

\section{Mediation of the effects of intergroup contact}

Given the research that suggests that intergroup contact experiences shape the valuing of diversity, it is possible that valuing diversity may mediate the effects of contact on other outcomes, such as prejudice and inclusive behaviors. Most mediation studies to date have focused on explaining the effect of intergroup contact on prejudice. When Pettigrew and Tropp (2008) conducted a meta-analysis of 54 papers, containing 91 samples, knowledge about the outgroup, intergroup empathy and anxiety were the mediators considered most frequently. They concluded that there is evidence for mediation through each of the three mediators. However, while the paths from contact to each of them had similar strength, knowledge was a much weaker predictor of prejudice than empathy and anxiety when controlling for contact, so that its contribution to explaining the association of contact with prejudice was much lower. In line with this finding, Pettigrew and Tropp concluded that "affective factors, such as anxiety reduction and empathy, are clearly major mediators relative to the more cognitively oriented mediator of knowledge" (2008, p. 929). However, given the importance of cognitive processes in the genesis of discriminatory beliefs and arrangements, other cognitive mediators deserve further study, with valuing diversity a prime candidate. 
Additionally, along with the general focus on positive contact throughout the literature (Barlow et al., 2012), much research on the mediation of contact effects has not taken contact valence into account. Consequently, little is known regarding the mediation of the effects of negative contact, even though there is some evidence that it follows a distinct pattern. For instance, Aberson (2015) found that intergroup threat is a more influential mediator for the effects of negative contact than for those of positive contact.

Furthermore, most mediation studies have focused on changes in prejudice, rather than changes in behavior and intentions, which are arguably more important when it comes to bringing about the social changes that motivate most research into intergroup relationships. However, there has been some work into the mediation of the links between contact and behavior/behavioral intentions. The effect of contact on bystander intervention intentions were mediated through empathy, in-group bias and cultural openness, but not through anxiety (Abbott \& Cameron, 2014). The effect on approach intentions was mediated through increased trust, improved attitudes and - in some analyses - reduced anxiety (Turner et al., 2013). The effect on helping intentions was mediated through anxiety (Hutchison \& Rosenthal, 2011). Finally, the effect on homophobic behaviors was mediated through reduced anxiety and reduced prejudice (Mereish \& Poteat, 2015). Overall, anxiety and intergroup attitudes emerge as the mediators with the strongest evidence base; (reactive) empathy and cognitive mediators have rarely been tested in this context.

Here, we consider the valuing of diversity as a mediator of the relationship between positive and negative contact, and both prejudice and behavioral intentions, to better understand the influence of this cognitive factor in different situations.

\section{The Present Research}

In three studies, one longitudinal and two cross-sectional, we examined the role 
of valuing diversity in intergroup contact. We first tested whether experiences of positive and negative contact predict changes in the value placed on diversity over time, and whether valuing diversity predicted future contact, thereby enabling a virtuous cycle (Study 1). We then considered whether valuing diversity mediates the association of positive and negative intergroup contact with a range of outcomes that address intergroup equity, first with a comprehensive analysis of various outcomes (cognitive and affective prejudice, as well as behavioural intentions) in a student sample (Study 2) and then a conceptual replication in a German probability sample (Study 3). Each study uses somewhat different measures for contact and valuing diversity, which offers an opportunity to conceptually replicate findings and to show the robustness of results.

\section{Study 1}

This study aimed to test the dynamic association between intergroup contact and valuing diversity. It extended earlier studies that had established an association (e.g., Harper \& Yeung, 2013; Tropp \& Bianchi, 2006) by employing a cross-lagged panel model to explore whether valuing diversity could combine with positive contact to form a virtuous cycle. The specific hypotheses were:

H1: Experiences of positive and negative contact predict positive and negative changes in the value placed on diversity over time.

H2: Valuing diversity predicts the experience of more positive contact over time.

Data and code for Study 1 are available at https://osf.io/sbpxj/?view_only=7d652e89096d4c39b8ca5de893ac384a. 


\section{Method}

\section{Participants and procedure}

The study required the estimation of a path model containing 15 paths. Given the frequent recommendation in the literature that the sample should contain at least 10 cases per parameter to be estimated (e.g., Jackson, 2003; Kline, 2015), we aimed for a sample size of at least 150 participants. To that end, we surveyed first-year psychology students in two English universities at the beginning of their first semester (T1, October) and again at the beginning of their second semester (T2, February). Only the responses from respondents who identified as White were considered; 211 such students responded to the survey at T1, out of which 151 returned at T2 (72\%). Eighty-one percent were female; the mean age was 19.4 years at $\mathrm{T} 1(S D=2.9$ years, range: 17 to 43 years). Participants received partial course credit for their participation. The two timepoints were approximately 110 days apart, which is in line with other recent studies concerning the longitudinal effects of intergroup contact (e.g., Meleady et al., 2020; Reimer et al., 2017).

\section{Measures}

In the surveys, we measured White students' contact with Black students. Black students were selected as the focal outgroup as they are the largest ethnic minority in the United Kingdom (3.9\% of 18-19 year-olds in England and Wales, GOV.UK, 2019) that can plausibly be treated as a single group. Though Asian British make up a greater share of the UK population, attitudes towards different Asian British groups (e.g., Indian, Bangladeshi and Pakistani), strongly diverge, rendering the overarching category less ideal for joint analysis (Ehsan, 2018). 
Contact. To measure positive and negative contact, we used the measure developed by Reimer and colleagues (2017). For negative contact, participants were asked how often they had been "ridiculed", "verbally abused", "made to feel unwanted", "intimidated" or "threatened" by Black British people, from $1=$ Never to 7 $=$ Very often, with Cronbach's $\alpha=.80$ at T1 and $\alpha=.86$ at T2. Likewise, positive contact was measured by asking how often participants had been "complimented", "befriended", "made to feel welcome", "supported" or "helped", from $1=$ Never to $7=$ Very often, with $\alpha=.87$ at $\mathrm{T} 1$ and $\alpha=.88$ at $\mathrm{T} 2$.

Valuing diversity. The value participants place on diversity was measured as the mean of three items adapted from Tropp and Bianchi (2006), asking to what extent they value it in British society, in their university and in their group of friends, from $1=$ Not at all to $7=$ Very much, with Cronbach's $\alpha=.89$ at $\mathrm{T} 1$ and $\alpha=.91$ at $\mathrm{T} 2$.

\section{Attrition and missing data}

As indicated above, 60 participants (28\%) who had responded to the survey at T1 did not return at T2. In order to test whether this missingness could be assumed to be completely at random, following Ridout (1991), we estimated a logistic regression with drop-out as the dependent variable and contact, valuing diversity, gender, age and university as predictors. This showed that women were less likely to drop out $(\mathrm{OR}=$ $0.32, p=.004)$, and students at University 2 were marginally more likely to drop out $(\mathrm{OR}=2.1, p=.08)$. The substantive variables were not related to drop-out, ORs $<=1.2$, $p \mathrm{~s}>.2$. Therefore, while missingness was not completely at random, it is unlikely to introduce substantial bias. Full-information maximum likelihood estimation was used, as it has been shown to avoid bias and maintain both power and proper rejection rates in longitudinal designs, even in cases of small samples with non-normal distributions (Shin et al., 2017). 


\section{Analytical approach}

Analyses were conducted using the lavaan 0.6-6 package (Rosseel, 2012) in R 4.0.1 (R Core Team, 2020), using the FIML estimator. Due to the limited sample size, no latent variables were used; instead, the scale averages were entered as observed variables. Fit indices cannot be obtained for two-wave cross-lagged panel models as these are fully saturated.

\section{Results}

Descriptive statistics and correlations between the variables are shown in Table 1. These were generally in line with expectations. It is worth noting that positive and negative contact were only weakly correlated at T1, $r=.16, p=.016$, and unrelated at $\mathrm{T} 2, r=-.05, p=.57$, confirming that they indeed represent distinct dimensions. Also, the estimated correlations between positive contact and valuing diversity were larger than those between negative contact and valuing diversity, even though this difference was only significant at $\mathrm{T} 1, p=.024$.

\section{[TABLE 1 AROUND HERE]}

\section{Longitudinal association between contact and valuing diversity}

In order to test Hypotheses 1 and 2, we estimated a cross-lagged panel model linking positive and negative contact experiences and the valuing of diversity. For that, we first estimated a multi-group model with separate parameters for the two universities and compared it to a model in which all parameters were constrained to be equal across the two universities. The more parsimonious constrained model did not show worse fit, $\chi^{2}(21)=12.98, p=.91$, so that a pooling of the samples was warranted. The resulting model is shown in Figure 1; paths not shown had $p$-values above .1 and the coefficients are fully standardised. All auto-regression paths were substantial and significant. 
Negative contact at T1 predicted lower valuing of diversity at T2, with $\beta=-0.19, p=$ $.014,95 \%$ CI [-0.33, -0.04], while more frequent positive contact had the opposite effect, with $\beta=0.16, p=.024,95 \%$ CI $[0.02,0.30]$. In the opposite direction, valuing diversity at $\mathrm{T} 1$ did not significantly predict positive contact at $\mathrm{T} 2$, with $\beta=0.10, p=$ $.13,95 \%$ CI $[-0.03,0.24]$ or negative contact at T2, with $\beta=-0.07, p=.35,95 \%$ CI [0.20, 0.07]. Full results are reported in Table 2.

[FIGURE 1 AROUND HERE]

[TABLE 2 AROUND HERE]

Therefore, Hypothesis 1 was supported; both positive and negative contact predicted changes in valuing diversity over time. Hypothesis 2 was not supported; over the period considered here, valuing diversity did not significantly predict the frequency of positive or negative intergroup contact.

\section{Discussion}

The results suggest that both positive and negative contact experiences shape the value students come to place on diversity over time. Therefore, it appears that intergroup contact is a promising avenue towards promoting the valuing of diversity, which has been associated with a variety of positive intergroup outcomes. Regarding the suggestion from earlier cross-sectional research that valuing diversity would also lead to more intergroup contact and thus fuel a virtuous cycle between contact and valuing diversity, our results are inconclusive: while the estimated paths from valuing diversity to future contact point in the expected direction, the coefficients are small and not statistically significant. While three months might have been too short to reveal an 
effect, the context of students' transition into their university life should have provided a favourable context for such an effect to emerge, given that most social relationships are in flux. Also, there were opportunities for increased contact with Black students at both universities; one had 5.5\% Black students, while the other had 13.2\% Black students, yet there was no evidence for different relationships between the variables in the two universities. Therefore, it appears warranted to focus on the effect of contact on valuing diversity and to explore the consequences of an increase in valuing diversity.

\section{Study 2}

This study tested whether valuing diversity can help explain (i.e. mediate) the association between (positive and negative) intergroup contact and a range of outcomes desirable for greater intergroup equity, namely the two key dimensions of prejudice (cognitive and affective) and two types of behavioral intentions (bystander intervention and policy support). The wide focus is based on the literature review that suggests that the role of specific mediators might depend on both the valence of contact and the outcomes under consideration. Pitting valuing diversity against empathy and anxiety, the two best established mediators from Pettigrew and Tropp (2008), in eight models of parallel mediation, enabled us to test whether valuing diversity is a relevant mediator and when its relevance might be particularly pronounced. We hypothesized that:

H3: There will be significant indirect paths through empathy, anxiety, and valuing diversity in each model, consistent with a hypothesis of parallel mediation.

More specifically, we expected that:

H4: The paths through valuing diversity will be stronger for the cognitive outcomes (cognitive prejudice and policy support) compared to the models for affective outcomes.

H5: Conversely, the paths through empathy and anxiety will be stronger in the 
affective rather than the cognitive models (i.e. for affective prejudice and bystander intervention intentions).

Data and code for Study 2 are available at https://osf.io/sbpxj/?view_only=7d652e89096d4c39b8ca5de893ac384a.

\section{Method}

\section{Participants}

Two hundred and twenty-four White undergraduate psychology students participated in this study (89\% females). All were either British citizens (95\%) or immigrants who intended to stay in the United Kingdom (5\%); international students who were only in the UK to attend university were excluded from the sample as the measures of cognitive prejudice and policy support were specific to the UK context. The participants' ages ranged from 18 to 50 years $(M=20.7, S D=4.8)$.

Participants were recruited in five universities in London and South East England to ensure that the sample covered a range of socio-economic contexts and different levels of ethnic diversity; across these universities, the share of minority-ethnic students among incoming British undergraduates ranged from $16.4 \%$ to $52.1 \%$, while the share of Black British students, specifically, ranged from $4.8 \%$ to $27.2 \%$, compared to a UK average of $22.7 \%$ for minority-ethnic and $7.0 \%$ for Black students (data for 2018/19 academic year, retrieved from Higher Education Statistics Agency, 2020). In two universities, the data was collected with paper questionnaires that students filled in during a lecture, while three universities administered it online as part of their research participation scheme. In four of the five universities, participants could receive partial course credits for their participation. 


\section{Measures}

Contact. The same measures for the frequency of positive and negative contact were used as in Study 1. Cronbach's $\alpha$ was .90 for positive and .91 for negative contact.

Mediators. Valuing diversity was measured with five items drawn from Adesokan et al. (2011), e.g., "Being a multi-ethnic nation is an advantage for achieving progress in the UK", $\alpha=.87$. Intergroup empathy was measured with two items taken from Swart et al. (2011), e.g., "If I saw a Black British person being treated unfairly, I think I would feel angry at the way they were being treated", Spearman-Brown reliability $=.84$. Finally, intergroup anxiety was measured in line with Turner et al. (2007) by asking participants to imagine "being put into a university hall of residence where you are living only with African and Caribbean British students" and reporting how they would feel on three semantic differentials, e.g., comfortable-tense, $\alpha=.87$.

Prejudice measures. For affective prejudice, participants rated how they generally feel towards Black British people on two five-point adjective scales: coldwarm and positive-negative (first reverse-coded, Spearman-Brown reliability $=.95$ ). Cognitive prejudice was measured with five statements of belief that covered attitudes (Katz \& Hass, 1988) and symbolic racism (Henry \& Sears, 2002), e.g., "Discrimination against Blacks is no longer a problem in the UK", $\alpha=.77$.

Behavioral intentions. Support for pro-diversity policies was measured with an original scale that asked for agreement with eight policies, e.g., "Government should use regulation to help minorities get better housing", $\alpha=.89$. Bystander intervention intentions were measured with a vignette that described a racist name-calling incident at a party and asked how likely participants were to show each of six possible reactions, adapted from Dickter, Kittel and Gyurovski (2012), e.g., "Tell the guy that his comment may be understood as offensive and that he might want to be more careful", $\alpha=.83$. 
Variables had at most $6.7 \%$ missing data. To retain power and avoid the potential for bias associated with listwise deletion, full-information maximum likelihood estimation was used, as this allows for cases with missing responses to be included (Shin et al., 2017). Analyses were conducted using the lavaan 0.6-6 package (Rosseel, 2012) in R 4.0.1 (R Core Team, 2020), with a model that replicates PROCESS Model 4 (Hayes, 2017). Bias-corrected confidence intervals for indirect effects and differences between correlation coefficients were bootstrapped with 5,000 resamples (MacKinnon et al., 2004).

\section{Results}

Table 3 shows descriptive statistics and correlations. Apart from the relationship between positive and negative contact, all correlations were significant and pointed in the expected direction, so that the hypothesized mediation models could be tested. It is worth noting that the estimated correlations tended to be larger for positive than negative contact; that difference was largest and marginally significant in the case of affective prejudice, which was more strongly correlated with positive than negative contact, diff: .20, 95\% CI [.00, .40]. Given that the frequencies of positive and negative contact were entirely unrelated, $r=-.01, p=.84$, there was no need to include both into the same mediation model. Thus, we estimated separate models for ease of comparison.

[TABLE 3 AROUND HERE]

\section{Tests of mediation}

[FIGURES 2a \& 2b AROUND HERE]

\section{[TABLE 4 AROUND HERE]}

Figures $2 \mathrm{a}$ and $2 \mathrm{~b}$ shows the mediation models associating contact with affective and cognitive outcomes, respectively, while the direct and indirect effects are summarized in Table 4. Contrary to our expectation that the three mediators would 
make a significant contribution to each model (Hypothesis 3), not all indirect paths were significant. However, collectively, the three mediators could explain most of the relationships between contact and each outcome (i.e. cognitive and affective prejudice, bystander intentions and policy support). After accounting for the mediators, none of the direct effects were significant and many estimates were close to zero.

With regard to the relative contributions of the mediators, the pattern of results generally matched our predictions. Valuing diversity was a significant mediator in six of the eight models; in line with Hypothesis 4, the indirect effects were particularly strong when it came to the cognitive outcomes, i.e. cognitive prejudice and policy support. Here, the paths through valuing diversity explained at least two thirds of the total effect. Empathy was a significant mediator in each of the eight models, though in line with Hypothesis 5, the indirect paths tended to be stronger for affective outcomes than cognitive outcomes. Anxiety, finally, more consistently mediated the effects of negative contact than positive contact, with the indirect effects reaching significance in three of the models for negative contact compared to just one for positive contact. Hypothesis 5 was partly confirmed in this regard: anxiety was a stronger mediator for affective prejudice than any of the other outcomes but contributed relatively little to explaining the effects of contact on bystander intervention intentions.

The pattern of results was similar for positive and negative contact, with the exception of the more consistent mediation of negative contact through anxiety and the generally smaller estimated effect sizes for negative contact, in line with the pattern of correlations already observed.

\section{Discussion}

The results of Study 2 were largely consistent with our expectations and suggest that valuing diversity should be considered alongside empathy and anxiety when it 
comes to the mediation of the effects of intergroup contact. It appears to be particularly important for cognitive outcomes, i.e. prejudicial beliefs and the support for policies that address inequalities and promote inclusion. Empathy, on the other hand, had more explanatory power for affective outcomes. Anxiety, finally, mediated a larger share of the effects of negative than positive contact, and was particularly relevant for explaining the effect of contact on affective prejudice. These findings expand upon prior research that concluded that cognitive mediators are of lower importance compared to affective mediators (Pettigrew \& Tropp, 2008), and suggest that a consideration of various outcomes of contact might reveal situations when cognitive mediators are particularly influential.

\section{Cognitive and affective outcomes - distinct patterns of mediation}

The mediation analyses highlighted the importance of considering different dimensions of prejudice. While the association of contact with affective prejudice could be largely explained through empathy and anxiety, with only a small contribution from valuing diversity, valuing diversity became an important mediator once the cognitive dimension of prejudice was considered. A similar pattern held true for behavioral intentions: while the relationship of contact with bystander intervention intentions, which we considered to be affective rather than cognitive in nature, was consistently mediated by empathy, valuing diversity became the strongest mediator when the links between contact and the support for inclusive policies was considered. Given that attitude and behavior change in both domains are needed to bring about a more integrated and equitable society, our results suggest that valuing diversity is a mediator worthy of further study. Conversely, the absence of substantial mediation through anxiety in all four models with cognitive outcomes suggests that the importance of this widely used mediator might be more restricted than often assumed. 


\section{Negative and positive contact - weak asymmetries}

It has been suggested that 'bad is stronger than good', i.e. that negative contact has a stronger effect than positive contact (Barlow et al., 2012), yet the evidence is mixed. In our results, with entirely unrelated measures of positive and negative contact $(r=-.04)$, the strength of the relationships between both types of contact, the mediators and the possible outcomes were similar. While most point estimates for negative contact were smaller than those for positive contact, these differences rarely reached statistical significance. Interestingly, the difference was most pronounced for affective prejudice, where the estimated total effect was twice as large for positive than negative contact, and entirely absent for cognitive prejudice, where the estimates were identical. This adds to the results of Aberson (2015) who found no asymmetry with regard to affective prejudice but a disproportionate impact of negative contact with regard to cognitive prejudice. Both sets of results suggest that comparatively, it becomes particularly important to consider negative contact when one is interested in cognitive aspects of prejudice, even though the effect of negative contact was generally weaker here than in Aberson (2015).

Given this evidence for the mediation of contact effects through valuing diversity in a UK student sample, we aimed to replicate the finding in a larger random population sample in a different national context. Study 3 offers this, and also addresses a potential limitation of Study 2 by including intergroup attitudes as a control mediator in explaining behavioral intentions.

\section{Study 3}

This study uses a random population sample from the German General Social Survey (ALLBUS) 2016 (GESIS, 2017) to test whether the mediation results replicate in a different context and in a larger, representative sample. ALLBUS again uses a 
different measure of valuing diversity, which allowed us to test whether the results are robust to different operationalizations of the construct. In addition, the larger sample allowed us to control for a mediation through attitudes towards foreigners to show that diversity beliefs are distinct. Specifically, we hypothesized that:

H6: Valuing diversity will predict participants' intergroup approach intentions (operationalized by the choice of diverse neighborhoods as potential places to live) and mediate the relationship between both positive and negative contact and that outcome.

H7: Valuing diversity will be a significant mediator alongside attitudes towards foreigners, which will also mediate some of the relationship between contact and approach intentions.

Code and data access instructions for Study 3 are available at https://osf.io/sbpxj/?view_only=7d652e89096d4c39b8ca5de893ac384a.

\section{Method}

\section{Dataset}

This study is based on data from the German General Social Survey (ALLBUS) 2016 (GESIS, 2017). The data was collected through computer-assisted personal interviewing during the summer of 2016. ALLBUS employs a random cluster sampling approach of residents of Germany above the age of 18 that covered 162 sample points and a total of 3,490 respondents in 2016, with a purposive oversampling of respondents from East Germany. For all analyses in this paper, the responses were weighted in line with the guidance in the variable report.

Only German citizens were asked about their intergroup contact experiences, thus only they were included in the analyses here, which led to the exclusion of 250 participants. Additionally, as a proxy for ethnicity (which is typically not collected in German surveys), only participants who reported that both their parents had been born 
in Germany (or in formerly German territories in Eastern Europe) were included. If participants reported the place of birth for only one of their parents, only that parent was considered. This led to the exclusion of another 409 participants. Finally, the contact measures we used asked for the frequency of positive and negative contact, which was not requested from participants who reported that they had not had any contact with foreigners, nor could it be meaningfully imputed for them. Therefore, those respondents were excluded, which led to a final 212 cases being dropped. This yielded a (weighted) sample size of 2,618 respondents $\left(M_{\mathrm{Age}}=50.8\right.$ years, $S D=17.4$ years, $49.3 \%$ female, $17.8 \%$ from East Germany).

\section{Measures}

Intergroup contact. Contact was measured with two items that asked how often people had made positive/negative experiences with foreigners (recoded to $1=$ never, 5 $=$ very often). In line with the findings of Studies 1 and 2, these items were only weakly correlated, $r=-.27, p<.001$, so that they could be treated as independent predictors.

Mediator: Diversity beliefs. Beliefs about the value of diversity for society were measured with two items: "A society with a high degree of cultural diversity is better able to tackle new problems" and "It is better for a country if all people belong to a common culture" (reversed). The Spearman-Brown reliability for a scale consisting of these two items was .59, which is acceptable for a two-item-scale, particularly if it includes reverse-coding (Loewenthal, 2001).

Control mediator: Attitudes towards foreigners. In order to ensure that diversity beliefs are not just a proxy for attitudes towards foreigners, we added these as a parallel mediator. They were measured with seven items, including "Foreigners are taking jobs away from Germans", "Foreigners help secure pensions" (reversed), and "The many foreign children in the schools prevent a good education for German children", all measured on a seven-point scale $(1=$ do not agree at all to $7=$ agree 
entirely). These items formed a consistent scale, with Cronbach's $\alpha$ of .80 .

Dependent variable: Approach intentions. Participants were shown

illustrations of 13 neighbourhoods, each made up of 49 house pictograms, that only differed in the share of white and black houses (the neighbourhoods contained between 0 and 48 black houses; cf. Figure 1 in Dirksmeier, 2014). They were not described further. Participants were then asked to select all neighbourhoods that they would like to live in. The neighbourhood with the highest number (i.e. the largest share of 'minority' houses) was taken as measuring approach intentions. ${ }^{1}$

Covariates. Age, gender and participants' level of education were included as demographic covariates, the latter coded following the ISCED 97 classification, from 1 $=$ basic education to $6=$ tertiary education, second stage. Due to their established association with diversity beliefs, participants' placement on a political ideology scale $(1=$ strongly on the left to $10=$ strongly on the right $)$ and their region of origin (West Germany or East Germany) $)^{2}$ were controlled for.

Finally, the share of foreigners in the current neighbourhood was controlled for. Here, ALLBUS conducted a survey experiment, asking half of the respondents to report the percentage freely while providing four categories to the other half $(1=($ Almost $)$ no foreigners to $4=$ Mostly foreigners). To combine these variables, the percentage

\footnotetext{
${ }^{1}$ Neighbourhood avoidance was also measured: Participants were presented with the remaining
} neighbourhoods and asked which of those they would not like to live in. Approach was the preferred outcome variable as it is less likely to be affected by social desirability, especially given the question ordering. However, in a supplementary analysis to test for robustness, the least diverse neighbourhood avoided above the most diverse neighbourhood approached was taken to express avoidance intentions; the findings were substantially the same (see Supplementary materials on the OSF).

${ }^{2}$ East Germany, the formerly socialist part, has a much more homogenous population than West Germany, with $4.4 \%$ of the population holding a foreign citizenship, compared to $12.6 \%$ in the West. In line with that, anti-foreigner attitudes and support for right-wing populism is more widespread in the East (Wallrich et al., 2020). 
responses were ranked and split into four categories in line with the proportions reported on the categorical question.

\section{Missing data and analytical approach}

$7.5 \%$ of cases had missing data on at least one of the variables under consideration. Political orientation was missing most frequently, at $3.4 \%$, all other variables were provided by at least $98.2 \%$ of participants. Nevertheless, listwise deletion would lead to a substantial loss of power and risk introducing bias. As fullinformation maximum-likelihood estimation is not supported by the lavaan package when survey weights are included, multiple imputation was used to retain all available information. This procedure creates multiple datasets in which missing values are differently imputed based on the observed data, thereby accounting for the uncertainty introduced by missing data (Rubin, 2004). Each dataset is then analyzed separately, before the results are aggregated to obtain the final parameter estimates and significance tests. The imputation was carried out using the mice package (Buuren \& GroothuisOudshoorn, 2010) in R (R Core Team, 2020), which uses a predictive mean modelling approach that is robust to possible non-normality. In line with guidance by White et al. (2011), eight imputations were used.

After multiple imputation, the analyses were performed with the lavaan.survey package (Oberski, 2014). Bootstrapping with survey weights is complex (Stapleton, 2008) and not yet implemented in lavaan.survey, while Monte-Carlo simulations have been shown to result in reliable confidence intervals for indirect effects in such situations (MacKinnon et al., 2004; Preacher \& Selig, 2012). Therefore, tests of indirect effects in this study are based on 20,000 Monte Carlo simulations, using the semTools $\mathrm{R}$ package (Jorgensen et al., 2019). 


\section{Results}

Descriptive statistics and correlations between the continous variables are shown in Table 5, while the distribution of categorical variables and their association with neighbourhood choice is shown in Table 6. Overall, approach intentions indicated through the choice of diverse neighbourhoods were related to valuing diversity and to the possible covariates with medium to large effect sizes (Cohen, 1988); only the links with negative contact and education were comparatively weak. Respondents in West Germany and those who had at least some foreigners in their current neighbourhood selected more diverse neighbourhoods. The measures of contact were associated both with neighbourhood choices and valuing diversity, so that the initial conditions for later tests of mediation were fulfilled.

\section{[TABLES 5 \& 6 AROUND HERE]}

Regarding potential asymmetries between positive and negative contact, it should be noted that the correlations between positive contact and its potential outcomes (approach, valuing diversity and attitudes towards foreigners) were larger than those for negative contact. Given that the confidence intervals in Table 5 do not overlap, these differences between the correlation coefficients were statistically significant.

\section{Test of the mediation}

We estimated a mediation model to test whether there were indirect paths from the contact measures through valuing diversity to approach intentions, in addition to the established path through attitudes towards foreigners, controlling for demographic covariates and political orientation in both the mediators and outcome variables. The resulting model is shown in Figure 3, while the coefficients for the direct and indirect paths are shown in Table 7. The model indicated that positive and negative contact had significant indirect effects on neighbourhood choice through both mediators, while the 
direct effect was only significant for positive contact. Overall, positive contact had a much stronger effect on approach intentions than negative contact did. Likewise, the mediation through valuing diversity was stronger for positive than negative contact, both in terms of the size of the indirect effect and its share of the total effect, because positive contact was more closely associated with valuing diversity than negative contact was.

[FIGURE 3 AROUND HERE]

\section{[TABLE 7 AROUND HERE]}

\section{Discussion}

In line with our hypotheses, valuing diversity was associated with the choice of more diverse neighbourhoods as potential places to live, and helped explain the association of positive and negative contact with these approach intentions. The observed data was consistent with a model in which valuing diversity mediated the relationships of positive contact and negative contact with approach intentions, in parallel with the mediation through attitudes towards foreigners and after controlling for a wide range of covariates. It is worth noting that the estimated indirect effects are small. However, small effects can have large social consequences when they shape many decisions that affect many people (Greenwald et al., 2015), as is arguably the case with decisions regarding everyday segregation. More specifically, with regard to neighbourhood choices, various simulation studies have shown that even relatively small preferences to live in neighbourhoods with many people of a similar ethnic background can lead to high levels of segregation (Schelling, 1971; Zhang, 2004).

Overall, this study thereby offers a conceptual replication of Study 2, using a random population sample with different measures and including a wide range of control variables. 


\section{General discussion}

It is established in the literature that a valuing of diversity leads to more positive intergroup relations, and that positive intergroup contact has the same effect. However, to date these literatures have rarely been linked. Among the studies that exist, valuing diversity has been presented both as a precursor to (Tropp \& Bianchi, 2006) and outcome of positive contact (Harper \& Yeung, 2013). Here, we explored this relationship further, particularly testing whether contact and valuing diversity may be linked in a virtuous cycle, in which beneficial outcomes of contact fuel further contact (Paolini et al., 2018), and whether valuing diversity might help explain how the effects of intergroup contact come about. Overall, we find that valuing diversity is shaped by contact, and that it might be an important mechanism through which beneficial contact effects come about. Conversely, we do not find evidence that valuing diversity operates as a precursor to contact.

Study 1 used longitudinal data to show that contact indeed predicts changes in valuing diversity over time. Positive and negative contact were measured as separate dimensions, and predicted increases and decreases in valuing diversity, respectively. This supported and expanded earlier research, which found that intergroup friendships were associated with an increased valuing of diversity (Harper \& Yeung, 2013). Valuing diversity did not have a significant effect on the future frequency of positive and negative intergroup contact, thereby failing to confirm the link proposed in earlier cross-sectional research (Bahns et al., 2015; Tropp \& Bianchi, 2006). While our null finding obviously does not rule out such an effect, the upper bound of the $95 \%$ confidence interval $(\beta=0.24)$ indicates that if there is an effect, it is unlikely to be strong. Nevertheless, this indicates a need for future research. Here, however, we focused on the stronger effect of contact on valuing diversity. 
whether valuing diversity could serve as a mediator of a range of contact effects. Again, we considered positive and negative contact as separate predictors and included four possible outcomes, namely affective and cognitive prejudice, bystander intervention intentions and support for policies that enhance intergroup equity. Valuing diversity mediated the associations of intergroup contact with all outcomes bar bystander intervention intentions. For cognitive outcome measures, it was the strongest mediator, indicating that earlier findings that cognitive mediators matter little (Pettigrew \& Tropp, 2008) might well be specific to affective outcomes. Empathy proved a significant moderator in all models, though with a rather small contribution to explaining cognitive outcomes. Anxiety, finally, more consistently mediated the effects of negative than positive contact, and primarily explained the effects of contact on affective prejudice.

Study 3 offered further support for the role of valuing diversity as a mediator of intergroup contact effects with a representative population sample and a wide range of demographic control variables. Again, we found significant effects of positive and negative contact on valuing diversity and support for the hypothesis that it can explain contact effects. When it comes to approach intentions, operationalized as the choice of diverse neighborhoods to live in, we found that valuing diversity is a significant mediator, this time tested alongside a measure of prejudice to ensure that valuing diversity is not just a proxy for attitudes towards 'diverse' others.

While our results suggest that contact effects partly come about through changes in valuing diversity, they do not establish how that pathway works. One possible explanation is that valuing diversity leads to a greater attentiveness to differences and thereby to greater salience of group memberships. Group salience has been shown to enhance contact effects in moderation studies (Oudenhoven et al., 1996; Voci \& Hewstone, 2003; see also Brown \& Hewstone, 2005), and might thus explain the mediation of the effects on prejudice. The mediation of the effects on policy support 
might be explained more directly: when diversity is valued, it appears reasonable to endorse policies that support its expression in society, be that directly or by affording opportunities to 'diverse' others, yet this also needs further testing.

\section{Limitations and future directions}

Some limitations of the present research should be highlighted. Firstly, the two waves of data collection in Study 1 were relatively close. While they took place in a context where social networks were in flux, this still limited the opportunity for valuing diversity to shape the frequency of contact experiences. Additionally, we only collected data at two points in time, which made it impossible to include random intercepts to entirely separate the within-person process from stable between-person differences (Hamaker et al., 2015). Future research should ideally follow participants over a longer period of time and over more points of data collection, so that the potential dynamic relationship between the variables can be explored more reliably.

Furthermore, cross-sectional analyses evidently cannot establish causality for the pathways in mediation models. However, testing whether the data is consistent with a hypothesis of mediation is a crucial step in the research process, as is the establishment of the temporal ordering of the variables, offered by Study 1 here. From there, experimental research that tests the causal direction of each step in the models would be a worthwhile future direction. Thus, experiments that test the impact of contact interventions on valuing diversity are needed, as are experiments that test the impact of diversity interventions (delivered in a way that does not backfire) on contact frequency and valence. Additionally, multi-wave longitudinal research that includes the mediators would allow for the estimation of indirect effects over time and thus add to our understanding of the relative contributions of various pathways.

Additionally, our conclusions are limited by the fact that we did not consider 
behaviors but rather behavioral intentions in the mediation studies, mostly because ecologically valid behaviors cannot be measured with paper-and-pencil questionnaires. While intentions and behaviors are clearly not the same, the link between them has been shown to be nearly twice as strong than the link between attitudes and discriminatory behaviors (Schütz \& Six, 1996). Thus, we expect that our findings regarding behavioral intentions would hold regarding behaviors, yet this is also a fruitful direction for future research.

Finally, the question whether valuing diversity shapes intergroup contact also deserves further attention. While our results in Study 1 suggest that it is unlikely to shape the frequency of positive and negative contact in the short term, the relatively close relationship between approach intentions and valuing diversity in Study $3(r=.40)$ replicate earlier findings of cross-sectional associations. It appears unlikely that this relationship never changes the structure of social networks, so that further research, for instance in the form of longitudinal work with other contact measures such as intergroup friendships, is needed.

\section{Conclusion}

Positive intergroup relations require that at least majority-status participants place a value on diversity. However, to date this has not systematically been linked with social psychology's most potent tool for prejudice reduction: intergroup contact. Across three studies, we show that positive experiences of intergroup contact increase the valuing of diversity while negative contact reduces it. This indicates that promoting positive contact might be a promising avenue towards developing an appreciation of diversity that does not run the risk of backfiring. Furthermore, valuing diversity then mediates the association of intergroup contact with a range of outcomes that can counter 
intergroup inequities, particularly when these outcomes are cognitive rather than affective in nature (e.g., cognitive prejudice and policy support). Overall, our results highlight an additional pathway through which intergroup contact can enhance intergroup relations. This provides a direction for future research and offers a specific lever that contact interventions can target to maximize their effect. 


\section{References}

Abbott, N., \& Cameron, L. (2014). What Makes a Young Assertive Bystander? The Effect of Intergroup Contact, Empathy, Cultural Openness, and In-Group Bias on Assertive Bystander Intervention Intentions: Predictors of Bystander Intervention Intentions. Journal of Social Issues, 70(1), 167-182. https://doi.org/10.1111/josi.12053

Aberson, C. L. (2015). Positive intergroup contact, negative intergroup contact, and threat as predictors of cognitive and affective dimensions of prejudice. Group Processes \& Intergroup Relations, 18(6), 743-760. https://doi.org/10.1177/1368430214556699

Adesokan, A. A., Ullrich, J., van Dick, R., \& Tropp, L. R. (2011). Diversity Beliefs as Moderator of the Contact-Prejudice Relationship. Social Psychology, 42(4), 271-278. https://doi.org/10.1027/1864-9335/a000058

Bagci, S. C., \& Turnuklu, A. (2018). Intended, Unintended, and Unknown Consequences of Contact. Social Psychology, 50(1), 7-23. https://doi.org/10.1027/1864-9335/a000355

Bahns, A. J. (2017). Preference, opportunity, and choice: A multilevel analysis of diverse friendship formation. Group Processes \& Intergroup Relations, 22(2), 233-252. https://doi.org/10.1177/1368430217725390

Bahns, A. J., Springer, L. S., \& The, C. (2015). Fostering diverse friendships: The role of beliefs about the value of diversity. Group Processes \& Intergroup Relations, 18(4), 475-488. https://doi.org/10.1177/1368430214566893

Barlow, F. K., Hornsey, M. J., Hayward, L. E., Houkamau, C. A., Kang, J., Milojev, P., \& Sibley, C. G. (2019). Why Do We Hold Mixed Emotions About Racial OutGroups? A Case for Affect Matching. Psychological Science, 30(6), 917-929. https://doi.org/10.1177/0956797619844269 
Barlow, F. K., Paolini, S., Pedersen, A., Hornsey, M. J., Radke, H. R. M., Harwood, J., Rubin, M., \& Sibley, C. G. (2012). The Contact Caveat: Negative Contact Predicts Increased Prejudice More Than Positive Contact Predicts Reduced Prejudice. Personality and Social Psychology Bulletin, 38(12), 1629-1643. https://doi.org/10.1177/0146167212457953

Berry, J. (2016). Diversity and equity. Cross Cultural \& Strategic Management, 23(3), 413-430. https://doi.org/10.1108/CCSM-03-2016-0085

Bilewicz, M., \& Soral, W. (2020). Hate Speech Epidemic. The Dynamic Effects of Derogatory Language on Intergroup Relations and Political Radicalization. Political Psychology. https://doi.org/10.1111/pops.12670

Binder, J., Zagefka, H., Brown, R., Funke, F., Kessler, T., Mummendey, A., Maquil, A., Demoulin, S., \& Leyens, J.-P. (2009). Does contact reduce prejudice or does prejudice reduce contact? A longitudinal test of the contact hypothesis among majority and minority groups in three european countries. Journal of Personality and Social Psychology, 96(4), 843-856. https://doi.org/10.1037/a0013470

Braddock, J. H., \& McPartland, J. M. (1989). Social-Psychological Processes That Perpetuate Racial Segregation: The Relationship Between School and Employment Desegregation. Journal of Black Studies, 19(3), 267-289. https://doi.org/10.1177/002193478901900301

Brown, R., \& Hewstone, M. (2005). An integrative theory of intergroup contact. Advances in Experimental Social Psychology, 37, 255-343. https://doi.org/10.1016/s0065-2601(05)37005-5

Buuren, S. van, \& Groothuis-Oudshoorn, K. (2010). mice: Multivariate imputation by chained equations in R. Journal of Statistical Software, 45(3), 1-68. https://doi.org/10.18637/jss.v045.i03

Cho, J., Tadmor, C. T., \& Morris, M. W. (2018). Are All Diversity Ideologies 
Creatively Equal? The Diverging Consequences of Colorblindness, Multiculturalism, and Polyculturalism. Journal of Cross-Cultural Psychology, 49(9), 1376-1401. https://doi.org/10.1177/0022022118793528

Cohen, J. (1988). Statistical Power Analysis for the Behavioral Sciences. Routledge.

Corrigan, P. W., Rowan, D., Green, A., Lundin, R., River, P., Uphoff-Wasowski, K., White, K., \& Kubiak, M. A. (2002). Challenging two mental illness stigmas: Personal responsibility and dangerousness. Schizophrenia Bulletin, 28(2), 293309.

Dessel, A. B., Goodman, K. D., \& Woodford, M. R. (2017). LGBT discrimination on campus and heterosexual bystanders: Understanding intentions to intervene. Journal of Diversity in Higher Education, 10(2), 101-116. https://doi.org/10.1037/dhe0000015

Dhont, K., Van Hiel, A., \& Hewstone, M. (2014). Changing the ideological roots of prejudice: Longitudinal effects of ethnic intergroup contact on social dominance orientation. Group Processes \& Intergroup Relations, 17(1), 27-44. https://doi.org/10.1177/1368430213497064

Dickter, C. L., Kittel, J. A., \& Gyurovski, I. I. (2012). Perceptions of non-target confronters in response to racist and heterosexist remarks. European Journal of Social Psychology, 42(1), 112-119. https://doi.org/10.1002/ejsp.855

Dixon, J., \& Durrheim, K. (2003). Contact and the ecology of racial division: Some varieties of informal segregation. British Journal of Social Psychology, 42(1), 123. https://doi.org/10.1348/014466603763276090

Dovidio, J. F., Gaertner, S. L., \& Kawakami, K. (2003). Intergroup Contact: The Past, Present, and the Future. Group Processes \& Intergroup Relations, 6(1), 5-21. https://doi.org/10.1177/1368430203006001009

Dys-Steenbergen, O., Wright, S. C., \& Aron, A. (2016). Self-expansion motivation 
improves cross-group interactions and enhances self-growth. Group Processes \& Intergroup Relations, 19(1), 60-71. https://doi.org/10.1177/1368430215583517

Emerson, M. O., Kimbro, R. T., \& Yancey, G. (2002). Contact Theory Extended: The Effects of Prior Racial Contact on Current Social Ties. Social Science Quarterly, 83(3), 745-761. https://doi.org/10.1111/1540-6237.00112

Fowers, B. J., \& Richardson, F. C. (1996). Why is multiculturalism good? American Psychologist, 51(6), 609-621. https://doi.org/10.1037/0003-066X.51.6.609

GESIS, L.-I. F. zialwissenschaften. (2017). Allgemeine Bevölkerungsumfrage der Sozialwissenschaften ALLBUS 2016 [Data set]. GESIS Data Archive. https://doi.org/10.4232/1.12796

GOV.UK. (2019). Ethnicity facts and figures: Age groups. https://www.ethnicity-factsfigures.service.gov.uk/uk-population-by-ethnicity/demographics/agegroups/latest\#data-sources

Graf, S., Paolini, S., \& Rubin, M. (2014). Negative intergroup contact is more influential, but positive intergroup contact is more common: Assessing contact prominence and contact prevalence in five Central European countries. European Journal of Social Psychology, 44(6), 536-547. https://doi.org/10.1002/ejsp.2052

Greenwald, A. G., Banaji, M. R., \& Nosek, B. A. (2015). Statistically small effects of the Implicit Association Test can have societally large effects. Journal of Personality and Social Psychology, 108(4), 553-561. https://doi.org/10.1037/pspa0000016

Hamaker, E. L., Kuiper, R. M., \& Grasman, R. P. P. P. (2015). A critique of the crosslagged panel model. Psychological Methods, 20(1), 102-116. https://doi.org/10.1037/a0038889 
Harper, C. E., \& Yeung, F. (2013). Perceptions of Institutional Commitment to Diversity as a Predictor of College Students' Openness to Diverse Perspectives. The Review of Higher Education, 37(1), 25-44. https://doi.org/10.1353/rhe.2013.0065

Hayes, A. F. (2017). Introduction to mediation, moderation, and conditional process analysis: A regression-based approach. Guilford publications.

Hayward, L. E., Tropp, L. R., Hornsey, M. J., \& Barlow, F. K. (2017). Toward a Comprehensive Understanding of Intergroup Contact: Descriptions and Mediators of Positive and Negative Contact Among Majority and Minority Groups. Personality and Social Psychology Bulletin, 43(3), 347-364. https://doi.org/10.1177/0146167216685291

Higher Education Statistics Agency. (2020). Who's studying in HE?: Personal characteristics. https://www.hesa.ac.uk/data-and-analysis/students/whos-inhe/characteristics

Hutchison, P., \& Rosenthal, H. E. S. (2011). Prejudice against Muslims: Anxiety as a mediator between intergroup contact and attitudes, perceived group variability and behavioural intentions. Ethnic and Racial Studies, 34(1), 40-61. https://doi.org/10.1080/01419871003763312

Jackson, D. L. (2003). Revisiting Sample Size and Number of Parameter Estimates: Some Support for the N:q Hypothesis. Structural Equation Modeling: A Multidisciplinary Journal, 10(1), 128-141. https://doi.org/10.1207/S15328007SEM1001_6

Johnston, B. M., \& Glasford, D. E. (2018). Intergroup contact and helping: How quality contact and empathy shape outgroup helping. Group Processes \& Intergroup Relations, 21(8), 1185-1201.

Jorgensen, T. D., Pornprasertmanit, S., Schoemann, A. M., \& Rosseel, Y. (2019). 
semTools: Useful tools for structural equation modeling. https://CRAN.Rproject.org/package=semTools

Kauff, M., \& Wagner, U. (2012). Valuable Therefore Not Threatening: The Influence of Diversity Beliefs on Discrimination Against Immigrants. Social Psychological and Personality Science, 3(6), 714-721. https://doi.org/10.1177/1948550611435942

Kline, R. B. (2015). Principles and Practice of Structural Equation Modeling, Fourth Edition. Guilford Publications.

Landmann, H., Gaschler, R., \& Rohmann, A. (2019). What is threatening about refugees? Identifying different types of threat and their association with emotional responses and attitudes towards refugee migration. European Journal of Social Psychology, 49(7), 1401-1420. https://doi.org/10.1002/ejsp.2593

Lemmer, G., \& Wagner, U. (2015). Can we really reduce ethnic prejudice outside the lab? A meta-analysis of direct and indirect contact interventions. European Journal of Social Psychology, 45(2), 152-168. https://doi.org/10.1002/ejsp.2079

Leslie, L. M., Bono, J. E., Kim, Y. (Sophia), \& Beaver, G. R. (2020). On melting pots and salad bowls: A meta-analysis of the effects of identity-blind and identityconscious diversity ideologies. Journal of Applied Psychology, 105(5), 453-471. https://doi.org/10.1037/ap10000446

Loewenthal, K. M. (2001). An introduction to psychological tests and scales. Psychology Press.

MacKinnon, D. P., Lockwood, C. M., \& Williams, J. (2004). Confidence Limits for the Indirect Effect: Distribution of the Product and Resampling Methods. Multivariate Behavioral Research, 39(1), 99-128. https://doi.org/10.1207/s15327906mbr3901_4

McKeown, S., Williams, A., \& Pauker, K. (2017). Stories that move them: Changing 
children's behaviour toward diverse peers. Journal of Community \& Applied Social Psychology, 27(5), 381-387. https://doi.org/10.1002/casp.2316

Meleady, R., \& Forder, L. (2019). When contact goes wrong: Negative intergroup contact promotes generalized outgroup avoidance. Group Processes \& Intergroup Relations, 22(5), 688-707. https://doi.org/10.1177/1368430218761568

Meleady, R., Seger, C., \& Vermue, M. (2020). Evidence of a dynamic association between intergroup contact and intercultural competence. Group Processes \& Intergroup Relations. https://doi.org/10.1177/1368430220940400

Mereish, E., \& Poteat, V. P. (2015). Effects of heterosexuals' direct and extended friendships with sexual minorities on their attitudes and behaviors: Intergroup anxiety and attitude strength as mediators and moderators. Journal of Applied Social Psychology, 45(3), 147-157. https://doi.org/10.1111/jasp.12284

Myers, P. C. (2019). The Case for Color-Blindness. The Heritage Foundation. https://www.heritage.org/civil-society/report/the-case-color-blindness

Oberski, D. (2014). lavaan.survey: An R Package for Complex Survey Analysis of Structural Equation Models. Journal of Statistical Software, 57(1), 1-27.

Osborn, H. J., Sosa, N., \& Rios, K. (2019). Perceiving demographic diversity as a threat: Divergent effects of multiculturalism and polyculturalism. Group Processes \& Intergroup Relations, 1368430219880606. https://doi.org/10.1177/1368430219880606

Oudenhoven, J. P. V., Groenewoud, J. T., \& Hewstone, M. (1996). Cooperation, ethnic salience and generalization of interethnic attitudes. European Journal of Social Psychology, 26(4), 649-661. https://doi.org/10.1002/(SICI)10990992(199607)26:4<649::AID-EJSP780>3.0.CO;2-T

Paolini, S., Harwood, J., Hewstone, M., \& Neumann, D. L. (2018). Seeking and 
avoiding intergroup contact: Future frontiers of research on building social integration. Social and Personality Psychology Compass, 12(12), e12422. https://doi.org/10.1111/spc3.12422

Paolini, S., \& McIntyre, K. (2019). Bad Is Stronger Than Good for Stigmatized, but Not Admired Outgroups: Meta-Analytical Tests of Intergroup Valence Asymmetry in Individual-to-Group Generalization Experiments. Personality and Social Psychology Review, 23(1), 3-47. https://doi.org/10.1177/1088868317753504

Pettigrew, T. F., \& Tropp, L. R. (2006). A meta-analytic test of intergroup contact theory. Journal of Personality and Social Psychology, 90(5), 751-783. https://doi.org/10.1037/0022-3514.90.5.751

Pettigrew, T. F., \& Tropp, L. R. (2008). How does intergroup contact reduce prejudice? Meta-analytic tests of three mediators. European Journal of Social Psychology, 38(6), 922-934. https://doi.org/10.1002/ejsp.504

Plant, E. A., Butz, D. A., \& Tartakovsky, M. (2008). Interethnic Interactions: Expectancies, Emotions, and Behavioral Intentions. Group Processes and Intergroup Relations, 11(4), 555-574. https://doi.org/10.1177/1368430208095827

Plaut, V. C., Garnett, F. G., Buffardi, L. E., \& Sanchez-Burks, J. (2011). "What about me?" Perceptions of exclusion and Whites' reactions to multiculturalism. Journal of Personality and Social Psychology, 101(2), 337-353. https://doi.org/10.1037/a0022832

Plaut, V. C., Thomas, K. M., Hurd, K., \& Romano, C. A. (2018). Do Color Blindness and Multiculturalism Remedy or Foster Discrimination and Racism? Current Directions in Psychological Science, 27(3), 200-206. https://doi.org/10.1177/0963721418766068

Preacher, K. J., \& Selig, J. P. (2012). Advantages of Monte Carlo Confidence Intervals 
for Indirect Effects. Communication Methods and Measures, 6(2), 77-98. https://doi.org/10.1080/19312458.2012.679848

R Core Team. (2020). R: A Language and Environment for Statistical Computing. R Foundation for Statistical Computing. https://www.R-project.org/

Reimer, N. K., Becker, J. C., Benz, A., Christ, O., Dhont, K., Klocke, U., Neji, S., Rychlowska, M., Schmid, K., \& Hewstone, M. (2017). Intergroup contact and social change: Implications of negative and positive contact for collective action in advantaged and disadvantaged groups. Personality and Social Psychology Bulletin, 43(1), 121-136. https://doi.org/10.1177/0146167216676478

Ridout, M. S. (1991). Testing for random dropouts in repeated measurement data. Biometrics, 47(4), 1617-1619. https://doi.org/10.2307/2532413

Rosenthal, L., \& Levy, S. R. (2012). The relation between polyculturalism and intergroup attitudes among racially and ethnically diverse adults. Cultural Diversity and Ethnic Minority Psychology, 18(1), 1-16. https://doi.org/10.1037/a0026490

Rosenthal, L., \& Levy, S. R. (2016). Endorsement of Polyculturalism Predicts Increased Positive Intergroup Contact and Friendship across the Beginning of College. Journal of Social Issues, 72(3), 472-488. https://doi.org/10.1111/josi.12177

Rosseel, Y. (2012). Lavaan: An R package for structural equation modeling and more. Version 0.5-12 (BETA). Journal of Statistical Software, 48(2), 1-36. https://doi.org/10.18637/jss.v048.i02

Rubin, D. B. (2004). Multiple imputation for nonresponse in surveys. John Wiley \& Sons.

Schelling, T. C. (1971). Dynamic models of segregation. Journal of Mathematical Sociology, 1(2), 143-186. https://doi.org/10.1080/0022250X.1971.9989794 Schlesinger, A. M. (1998). The disuniting of America: Reflections on a multicultural 
society. WW Norton \& Company.

Schütz, H., \& Six, B. (1996). How strong is the relationship between prejudice and discrimination? A meta-analytic answer. International Journal of Intercultural Relations, 20(3), 441-462. https://doi.org/10.1016/0147-1767(96)00028-4

Selvanathan, H. P., Techakesari, P., Tropp, L. R., \& Barlow, F. K. (2017). Whites for racial justice: How contact with Black Americans predicts support for collective action among White Americans. Group Processes \& Intergroup Relations, 1368430217690908. https://doi.org/10.1177/1368430217690908

Shin, T., Davison, M. L., \& Long, J. D. (2017). Maximum likelihood versus multiple imputation for missing data in small longitudinal samples with nonnormality. Psychological Methods, 22(3), 426-449. https://doi.org/10.1037/met0000094

Stapleton, L. M. (2008). Variance Estimation Using Replication Methods in Structural Equation Modeling With Complex Sample Data. Structural Equation Modeling: A Multidisciplinary Journal, 15(2), 183-210. https://doi.org/10.1080/10705510801922316

Stürmer, S., Benbow, A. E. F., Siem, B., Barth, M., Bodansky, A. N., \& Lotz-Schmitt, K. (2013). Psychological foundations of xenophilia: The role of major personality traits in predicting favorable attitudes toward cross-cultural contact and exploration. Journal of Personality and Social Psychology, 105(5), 832851. https://doi.org/10.1037/a0033488

Swart, H., Hewstone, M., Christ, O., \& Voci, A. (2011). Affective mediators of intergroup contact: A three-wave longitudinal study in South Africa. Journal of Personality and Social Psychology, 101(6), 1221-1238. https://doi.org/10.1037/a0024450

Tropp, L. R., \& Bianchi, R. A. (2006). Valuing diversity and interest in intergroup contact. Journal of Social Issues, 62(3), 533-551. 
https://doi.org/10.1111/j.1540-4560.2006.00472.x

Tropp, L. R., \& Pettigrew, T. F. (2005). Differential Relationships Between Intergroup Contact and Affective and Cognitive Dimensions of Prejudice. Personality and Social Psychology Bulletin, 31(8), 1145-1158. https://doi.org/10.1177/0146167205274854

Turner, R. N., Hewstone, M., \& Voci, A. (2007). Reducing explicit and implicit outgroup prejudice via direct and extended contact: The mediating role of selfdisclosure and intergroup anxiety. Journal of Personality and Social Psychology, 93(3), 369-388. https://doi.org/10.1037/0022-3514.93.3.369

Turner, R. N., West, K., \& Christie, Z. (2013). Out-group trust, intergroup anxiety, and out-group attitude as mediators of the effect of imagined intergroup contact on intergroup behavioral tendencies. Journal of Applied Social Psychology, 43(S2), E196-E205. https://doi.org/10.1111/jasp.12019

Vertovec, S. (2007). Super-diversity and its implications. Ethnic and Racial Studies, 30(6), 1024-1054. https://doi.org/10.1080/01419870701599465

Vertovec, S., \& Wessendorf, S. (2010). The multiculturalism backlash: European discourses, policies, and practices. Routledge.

Visintin, E. P., Voci, A., Pagotto, L., \& Hewstone, M. (2017). Direct, extended, and mass-mediated contact with immigrants in Italy: Their associations with emotions, prejudice, and humanity perceptions. Journal of Applied Social Psychology, 47(4), 175-194. https://doi.org/10.1111/jasp.12423

Voci, A., \& Hewstone, M. (2003). Intergroup contact and prejudice toward immigrants in Italy: The mediational role of anxiety and the moderational role of group salience. Group Processes \& Intergroup Relations, 6(1), 37-54. https://doi.org/10.1177/1368430203006001011

Wallrich, L., West, K., \& Rutland, A. (2020). Painting All Foreigners With One Brush? 
How the Salience of Muslims and Refugees Shapes Judgements. Journal of Social and Political Psychology, 8(1), 246-265-265. https://doi.org/10.5964/jspp.v8i1.1283

Wallrich, L., West, K., \& Rutland, A. (2020). Painting All Foreigners With One Brush? How the Salience of Muslims and Refugees Shapes Judgements. Journal of Social and Political Psychology, 8(1), 246-265-265. https://doi.org/10.5964/jspp.v8i1.1283

White, I. R., Royston, P., \& Wood, A. M. (2011). Multiple imputation using chained equations: Issues and guidance for practice. Statistics in Medicine, 30(4), 377399. https://doi.org/10.1002/sim.4067

Wilton, L. S., Apfelbaum, E. P., \& Good, J. J. (2019). Valuing Differences and Reinforcing Them: Multiculturalism Increases Race Essentialism. Social Psychological and Personality Science, 10(5), 681-689. https://doi.org/10.1177/1948550618780728

Wölfer, R., Jaspers, E., Blaylock, D., Wigoder, C., Hughes, J., \& Hewstone, M. (2017). Studying Positive and Negative Direct and Extended Contact: Complementing Self-Reports With Social Network Analysis. Personality and Social Psychology Bulletin, 43(11), 1566-1581. https://doi.org/10.1177/0146167217719732

Yogeeswaran, K., Verkuyten, M., \& Ealam, B. (2020). A way forward? The impact of interculturalism on intergroup relations in culturally diverse nations. Group Processes \& Intergroup Relations, 1368430220918651. https://doi.org/10.1177/1368430220918651

Zhang, J. (2004). A Dynamic Model of Residential Segregation. The Journal of Mathematical Sociology, 28(3), 147-170. https://doi.org/10.1080/00222500490480202 


\section{Tables}

\section{Table 1.}

Descriptive Statistics and Correlations for Study 1

\begin{tabular}{|c|c|c|c|c|c|c|}
\hline Variable & $M(S D)$ & 1.1 & 1.2 & 2.1 & 2.2 & 3.1 \\
\hline 1.1 Positive contact ${ }^{\mathrm{T} 1}$ & $4.41(1.43)$ & & & & & \\
\hline 1.2 Positive contact ${ }^{\mathrm{T} 2}$ & $4.51(1.35)$ & $\begin{array}{l}.54 * * * \\
{[.43, .66]}\end{array}$ & & & & \\
\hline 2.1 Negative contact ${ }^{\mathrm{T} 1}$ & $1.76(0.95)$ & $\begin{array}{l}.16 * \\
{[.03, .30]}\end{array}$ & $\begin{array}{l}.08 \\
{[-.08, .24]}\end{array}$ & & & \\
\hline 2.2 Negative contact ${ }^{\mathrm{T} 2}$ & $1.87(1.01)$ & $\begin{array}{l}.05 \\
{[-.11, .20]}\end{array}$ & $\begin{array}{l}-.05 \\
{[-.21, .11]}\end{array}$ & $\begin{array}{l}.55 * * * \\
{[.44, .67]}\end{array}$ & & \\
\hline 3.1 Valuing diversity ${ }^{\mathrm{T} 1}$ & $6.14(1.02)$ & $\begin{array}{l}.22 * * \\
{[.09, .35]}\end{array}$ & $\begin{array}{l}.22 * * \\
{[.07, .36]}\end{array}$ & $\begin{array}{l}-.02 \\
{[-.16, .12]}\end{array}$ & $\begin{array}{l}-.08 \\
{[-.23, .07]}\end{array}$ & \\
\hline 3.2 Valuing diversity ${ }^{\mathrm{T} 2}$ & $5.74(1.11)$ & $\begin{array}{l}.22 * * \\
{[.08, .37]}\end{array}$ & $\begin{array}{l}.33 * * * \\
{[.19, .47]}\end{array}$ & $\begin{array}{l}-.17 * \\
{[-.33,-.01]}\end{array}$ & $\begin{array}{l}-.28 * * * \\
{[-.43,-.13]}\end{array}$ & $\begin{array}{l}.46 * * * \\
{[.34, .58]}\end{array}$ \\
\hline
\end{tabular}

Notes. $M$ and $S D$ are used to represent mean and standard deviation, respectively.

Values in square brackets indicate the $95 \%$ confidence interval for each correlation.

T1: Measured at timepoint 1

T2: Measured at timepoint 2

$* \mathrm{p}<.05, * * \mathrm{p}<.01, * * * \mathrm{p}<.001$ 
RUNNING HEAD: Intergroup contact and valuing diversity

Table 2.

Results of the Cross-Lagged Panel Model Connecting Contact and Valuing Diversity

\begin{tabular}{llllllll}
\hline & \multicolumn{2}{c}{ Valuing diversity (T2) } & \multicolumn{2}{c}{ Positive contact (T2) } & \multicolumn{2}{c}{ Negative contact (T2) } \\
Predictor & $\boldsymbol{\beta}[\mathbf{9 5 \%}$ CI $]$ & $\boldsymbol{p}$ & $\boldsymbol{\beta}[\mathbf{9 5 \%}$ CI $]$ & $\boldsymbol{p}$ & $\boldsymbol{\beta}[\mathbf{9 5 \%}$ CI $]$ & $\boldsymbol{p}$ \\
\hline Valuing diversity (T1) & $0.42[0.28,0.56]$ & $<.001$ & $0.10[-0.03,0.24]$ & .133 & $-0.07[-0.20,0.07]$ & .353 \\
\hline Positive contact (T1) & $0.16[0.02,0.30]$ & .024 & $0.52[0.38,0.66]$ & $<.001$ & $-0.03[-0.17,0.11]$ & .666 \\
\hline Negative contact (T1) & $-0.19[-0.33,-0.04]$ & .014 & $-0.00[-0.15,0.14]$ & .959 & $0.56[0.42,0.71]$ & $<.001$ \\
\hline
\end{tabular}

Notes:

Standardised coefficients estimated with full-information maximum-likelihood.

T1: Measured at timepoint 1

T2: Measured at timepoint 2 
Table 3.

Descriptive Statistics and Correlations for Study 2

\begin{tabular}{|c|c|c|c|c|c|c|c|c|c|}
\hline Variable & $M(S D)$ & 1 & 2 & 3 & 4 & 5 & 6 & 7 & 8 \\
\hline 1. Pos. contact & $4.26(1.34)$ & & & & & & & & \\
\hline 2. Neg. contact & $2.14(1.19)$ & $\begin{array}{l}-.01 \\
{[-.15, .12]}\end{array}$ & & & & & & & \\
\hline 3. Valuing diversity & $5.48(1.09)$ & $\begin{array}{l}.43 * * * \\
{[.28, .57]}\end{array}$ & $\begin{array}{l}-.30 * * * \\
{[-.44,-.16]}\end{array}$ & & & & & & \\
\hline 4. Empathy & $5.81(1.16)$ & $\begin{array}{l}.33 * * * \\
{[.19, .47]}\end{array}$ & $\begin{array}{l}-.19 * * \\
{[-.32,-.05]}\end{array}$ & $\begin{array}{l}.49 * * * \\
{[.35, .64]}\end{array}$ & & & & & \\
\hline 5. Anxiety & $2.44(0.96)$ & $\begin{array}{l}-.34 * * * \\
{[-.48,-.20]}\end{array}$ & $\begin{array}{l}.30 * * * \\
{[.16, .44]}\end{array}$ & $\begin{array}{l}-.36 * * * \\
{[-.50,-.21]}\end{array}$ & $\begin{array}{l}-.22 * * \\
{[-.36,-.09]}\end{array}$ & & & & \\
\hline 6. Cognitive prejudice & $2.77(0.99)$ & $\begin{array}{l}-.20 * * \\
{[-.34,-.07]}\end{array}$ & $\begin{array}{l}.21 * * \\
{[.08, .35]}\end{array}$ & $\begin{array}{l}-.55 * * * \\
{[-.70,-.40]}\end{array}$ & $\begin{array}{l}-.34 * * * \\
{[-.48,-.20]}\end{array}$ & $\begin{array}{l}.27 * * * \\
{[.13, .41]}\end{array}$ & & & \\
\hline 7. Affective prejudice & $1.76(0.81)$ & $\begin{array}{l}-.38 * * * \\
{[-.53,-.24]}\end{array}$ & $\begin{array}{l}.18 * * \\
{[.04, .32]}\end{array}$ & $\begin{array}{l}-.44 * * * \\
{[-.58,-.29]}\end{array}$ & $\begin{array}{l}-.49 * * * \\
{[-.64,-.35]}\end{array}$ & $\begin{array}{l}.45 * * * \\
{[.31, .60]}\end{array}$ & $\begin{array}{l}.33 * * * \\
{[.19, .47]}\end{array}$ & & \\
\hline 8. Bystander intervention & $5.04(1.20)$ & $\begin{array}{l}.25 * * * \\
{[.12, .39]}\end{array}$ & $\begin{array}{l}-.15 * \\
{[-.29,-.02]}\end{array}$ & $\begin{array}{l}.38 * * * \\
{[.24, .52]}\end{array}$ & $\begin{array}{l}.39 * * * \\
{[.25, .53]}\end{array}$ & $\begin{array}{l}-.29 * * * \\
{[-.42,-.15]}\end{array}$ & $\begin{array}{l}-.34 * * * \\
{[-.47,-.20]}\end{array}$ & $\begin{array}{l}-.38 * * * \\
{[-.52,-.24]}\end{array}$ & \\
\hline 9. Policy support & $5.28(1.00)$ & $\begin{array}{l}.35 * * * \\
{[.21, .49]}\end{array}$ & $\begin{array}{l}-.24 * * * \\
{[-.37,-.10]}\end{array}$ & $\begin{array}{l}.69 * * * \\
{[.53, .85]}\end{array}$ & $\begin{array}{l}.46 * * * \\
{[.31, .60]}\end{array}$ & $\begin{array}{l}-.34 * * * \\
{[-.48,-.20]}\end{array}$ & $\begin{array}{l}-.59 * * * \\
{[-.74,-.43]}\end{array}$ & $\begin{array}{l}-.45 * * * \\
{[-.59,-.30]}\end{array}$ & $\begin{array}{l}.41 * * * \\
{[.27, .55]}\end{array}$ \\
\hline
\end{tabular}

Notes. $M$ and $S D$ are used to represent mean and standard deviation, respectively. Values in square brackets indicate the $95 \%$ confidence intervals.

$* \mathrm{p}<.05, * * \mathrm{p}<.01, * * * \mathrm{p}<.001$ 


\section{Table 4.}

Direct and Indirect Paths from Contact to Various Potential Outcomes

\begin{tabular}{|c|c|c|c|c|c|c|}
\hline \multirow[b]{2}{*}{ From } & \multirow[b]{2}{*}{ To } & \multirow[b]{2}{*}{ direct } & \multicolumn{3}{|c|}{ Indirect through ... } & \multirow[b]{2}{*}{ total } \\
\hline & & & Anxiety & Val. diversity & Empathy & \\
\hline \multirow[t]{4}{*}{$\begin{array}{l}\text { Pos. } \\
\text { contact }\end{array}$} & $\begin{array}{l}\text { Affective } \\
\text { prejudice }\end{array}$ & $\begin{array}{l}-.12 \dagger \\
{[-0.24,0.00]}\end{array}$ & $\begin{array}{l}\mathbf{- . 1 1} \\
{[-0.27,-0.06]}\end{array}$ & $\begin{array}{l}-.05 \\
{[-0.13,-0.01]}\end{array}$ & $\begin{array}{l}\mathbf{- . 1 1} \\
{[-0.23,-0.05]}\end{array}$ & $\begin{array}{l}-.39 * * * \\
{[-0.57,-0.21]}\end{array}$ \\
\hline & $\begin{array}{l}\text { Cognitive } \\
\text { prejudice }\end{array}$ & $\begin{array}{l}.08 \\
{[-0.05,0.21]}\end{array}$ & $\begin{array}{l}-.04 \\
{[-0.11,0.01]}\end{array}$ & $\begin{array}{l}-.22 \\
{[-0.30,-0.12]}\end{array}$ & $\begin{array}{l}-.03 \\
{[-0.11,-0.01]}\end{array}$ & $\begin{array}{l}-.21 * * * \\
{[-0.31,-0.09]}\end{array}$ \\
\hline & $\begin{array}{l}\text { Bystander } \\
\text { intervention }\end{array}$ & $\begin{array}{l}.04 \\
{[-0.10,0.17]}\end{array}$ & $\begin{array}{l}.05 \\
{[-0.01,0.11]}\end{array}$ & $\begin{array}{l}.08 \\
{[-0.01,0.17]}\end{array}$ & $\begin{array}{l}.09 \\
{[0.06,0.15]}\end{array}$ & $\begin{array}{l}.26 * * * \\
{[0.17,0.38]}\end{array}$ \\
\hline & $\begin{array}{l}\text { Policy } \\
\text { support }\end{array}$ & $\begin{array}{l}.01 \\
{[-0.10,0.12]}\end{array}$ & $\begin{array}{l}.03 \\
{[-0.04,0.07]}\end{array}$ & $\begin{array}{l}.26 \\
{[0.14,0.35]}\end{array}$ & $\begin{array}{l}. \mathbf{0 5} \\
{[0.01,0.11]}\end{array}$ & $\begin{array}{l}.35 * * * \\
{[0.19,0.44]}\end{array}$ \\
\hline \multirow[t]{4}{*}{$\begin{array}{l}\text { Neg. } \\
\text { contact }\end{array}$} & $\begin{array}{l}\text { Affective } \\
\text { prejudice }\end{array}$ & $\begin{array}{l}-.03 \\
{[-0.15,0.08]}\end{array}$ & $\begin{array}{l}\mathbf{. 1 0} \\
{[0.03,0.24]}\end{array}$ & $\begin{array}{l}. \mathbf{0 5} \\
{[0.00,0.12]}\end{array}$ & $\begin{array}{l}.07 \\
{[0.02,0.13]}\end{array}$ & $\begin{array}{l}.19 * \\
{[0.04,0.38]}\end{array}$ \\
\hline & $\begin{array}{l}\text { Cognitive } \\
\text { prejudice }\end{array}$ & $\begin{array}{l}.03 \\
{[-0.09,0.15]}\end{array}$ & $\begin{array}{l}.02 \\
{[-0.02,0.11]}\end{array}$ & $\begin{array}{l}. \mathbf{1 4} \\
{[0.08,0.23]}\end{array}$ & $\begin{array}{l}.02 \\
{[0.00,0.05]}\end{array}$ & $\begin{array}{l}.21 * * \\
{[0.06,0.35]}\end{array}$ \\
\hline & $\begin{array}{l}\text { Bystander } \\
\text { intervention }\end{array}$ & $\begin{array}{l}.01 \\
{[-0.12,0.13]}\end{array}$ & $\begin{array}{l}\mathbf{- . 0 5} \\
{[-0.10,-0.01]}\end{array}$ & $\begin{array}{l}-.06 \\
{[-0.12,0.00]}\end{array}$ & $\begin{array}{l}\mathbf{- . 0 5} \\
{[-0.09,-0.01]}\end{array}$ & $\begin{array}{l}-.16 * \\
{[-0.32,0.04]}\end{array}$ \\
\hline & $\begin{array}{l}\text { Policy } \\
\text { support }\end{array}$ & $\begin{array}{l}-.00 \\
{[-0.10,0.10]}\end{array}$ & $\begin{array}{l}-\mathbf{. 0 3} \\
{[-0.14,-0.01]}\end{array}$ & $\begin{array}{l}\mathbf{- . 1 8} \\
{[-0.28,-0.10]}\end{array}$ & $\begin{array}{l}-\mathbf{. 0 3} \\
{[-0.08,-0.01]}\end{array}$ & $\begin{array}{l}-.24 * * * \\
{[-0.43,-0.11]}\end{array}$ \\
\hline
\end{tabular}

Notes.

Standardized coefficients, estimated with full-information maximum likelihood. 95\% confidence intervals for indirect effects based on bias-corrected bootstraps with 5,000 resamples, indirect effects with confidence intervals that do not cross 0 are bolded.

Val. diversity = valuing diversity .

$\dagger p<.1, * p<.05, * * p<.01, * * * p<.001$ 


\section{Table 5.}

Descriptive statistics and correlations

\begin{tabular}{|c|c|c|c|c|c|c|c|c|c|}
\hline Variable & $M(S D)$ & 1 & 2 & 3 & 4 & 5 & 6 & 7 & 8 \\
\hline 1. Approach intentions & $\begin{array}{l}5.42 \\
(2.66)\end{array}$ & & & & & & & & \\
\hline 2. Valuing diversity & $\begin{array}{l}-0.07 \\
(0.73)\end{array}$ & $\begin{array}{l}.40 * * * \\
{[.37, .43]}\end{array}$ & & & & & & & \\
\hline 3. Attitude towards foreigners & $\begin{array}{l}4.30 \\
(1.22)\end{array}$ & $\begin{array}{l}.53 * * * \\
{[.50, .56]}\end{array}$ & $\begin{array}{l}.53 * * * \\
{[.50, .55]}\end{array}$ & & & & & & \\
\hline 4. Political Orientation & $\begin{array}{l}5.88 \\
(1.70)\end{array}$ & $\begin{array}{l}.28 * * * \\
{[.24, .33]}\end{array}$ & $\begin{array}{l}.27 * * * \\
{[.22, .31]}\end{array}$ & $\begin{array}{l}.31 * * * \\
{[.26, .35]}\end{array}$ & & & & & \\
\hline 5. Age & $\begin{array}{l}51.82 \\
(17.62)\end{array}$ & $\begin{array}{l}-.36 * * * \\
{[-.40,-.33]}\end{array}$ & $\begin{array}{l}-.09 * * * \\
{[-.13,-.06]}\end{array}$ & $\begin{array}{l}-.14 * * * \\
{[-.17,-.10]}\end{array}$ & $\begin{array}{l}-.04 * \\
{[-.08,-.00]}\end{array}$ & & & & \\
\hline 6. Education & $\begin{array}{l}3.78 \\
(1.07)\end{array}$ & $\begin{array}{l}.18 * * * \\
{[.15, .22]}\end{array}$ & $\begin{array}{l}.14 * * * \\
{[.11, .18]}\end{array}$ & $\begin{array}{l}.19 * * * \\
{[.16, .23]}\end{array}$ & $\begin{array}{l}.10 * * * \\
{[.06, .13]}\end{array}$ & $\begin{array}{l}.02 \\
{[-.01, .06]}\end{array}$ & & & \\
\hline 7. Positive contact & $\begin{array}{l}3.88 \\
(1.01)\end{array}$ & $\begin{array}{l}.39 * * * \\
{[-.43,-.35]}\end{array}$ & $\begin{array}{l}.35 * * * \\
{[-.40,-.30]}\end{array}$ & $\begin{array}{l}.43 * * * \\
{[-.47,-.40]}\end{array}$ & $\begin{array}{l}.20 * * * \\
{[-.27,-.13]}\end{array}$ & $\begin{array}{l}-.15 * * * \\
{[.09, .20]}\end{array}$ & $\begin{array}{l}.20 * * * \\
{[-.24,-.16]}\end{array}$ & & \\
\hline 8. Negative contact & $\begin{array}{l}2.14 \\
(0.99)\end{array}$ & $\begin{array}{l}-.10 * * * \\
{[.04, .15]}\end{array}$ & $\begin{array}{l}-.16 * * * \\
{[.10, .22]}\end{array}$ & $\begin{array}{l}-.26 * * * \\
{[.20, .32]}\end{array}$ & $\begin{array}{l}-.16 * * * \\
{[.10, .22]}\end{array}$ & $\begin{array}{l}-.19 * * * \\
{[.14, .24]}\end{array}$ & $\begin{array}{l}-.04 * \\
{[-.02, .10]}\end{array}$ & $\begin{array}{l}.25 * * * \\
{[-.32,-.18]}\end{array}$ & \\
\hline 9. Contact frequency & $\begin{array}{l}2.79 \\
(1.23)\end{array}$ & $\begin{array}{l}.38 * * * \\
{[.35, .41]}\end{array}$ & $\begin{array}{l}.21 * * * \\
{[.17, .25]}\end{array}$ & $\begin{array}{l}.29 * * * \\
{[.26, .33]}\end{array}$ & $\begin{array}{l}.09 * * * \\
{[.05, .13]}\end{array}$ & $\begin{array}{l}-.33 * * * \\
{[-.37,-.30]}\end{array}$ & $\begin{array}{l}.18 * * * \\
{[.14, .21]}\end{array}$ & $\begin{array}{l}-.38 * * * \\
{[-.45,-.31]}\end{array}$ & $\begin{array}{l}-.13 * * * \\
{[-.23,-.03]}\end{array}$ \\
\hline
\end{tabular}

Notes: $M$ and $S D$ are used to represent mean and standard deviation, respectively. Values in square brackets indicate the $95 \%$ confidence interval for each correlation.

$\dagger p<.1, * p<.05, * * p<.01, * * * p<.001$ 


\section{Table 6.}

Descriptive statistics and associations for categorical variables

\begin{tabular}{lrrl}
\hline & N & Share & $M(S D)$ approach intentions \\
\hline Gender & & & \\
\hline female & 1412 & $49.8 \%$ & $5.47(2.55)^{\mathrm{a}}$ \\
male & 1423 & $50.2 \%$ & $5.37(2.75)^{\mathrm{a}}$ \\
\hline Region & & & \\
\hline East Germany & 571 & $20.1 \%$ & $4.44(2.51)^{\mathrm{b}}$ \\
West Germany & 2264 & $79.9 \%$ & $5.67(2.63)^{\mathrm{a}}$ \\
\hline Foreigners in neighborhood & & \\
\hline (Almost) no foreigners & 955 & $33.7 \%$ & $4.83(2.48)^{\mathrm{b}}$ \\
Some foreigners & 1524 & $53.8 \%$ & $5.66(2.62)^{\mathrm{a}}$ \\
Many foreigners & 316 & $11.1 \%$ & $6.06(2.94)^{\mathrm{a}}$ \\
Mostly foreigners & 40 & $1.4 \%$ & $5.30(3.14)^{\mathrm{ab}}$ \\
\hline
\end{tabular}

Notes: $M$ and $S D$ are used to represent mean and standard deviation for approach intentions for that group, respectively. Within each variable, the means of groups with different superscripts differ with $p<$ .05 ( $p$-values were adjusted using the Holm-method.) 
Table 7.

Mediation of the effect of intergroup contact on neighborhood choice

\begin{tabular}{|c|c|c|c|c|}
\hline \multirow[t]{3}{*}{ Predictor } & \multicolumn{4}{|c|}{ Paths (standardized coefficients) } \\
\hline & \multirow[t]{2}{*}{ Direct } & \multicolumn{2}{|c|}{ Indirect through } & \multirow[t]{2}{*}{ Total } \\
\hline & & $\begin{array}{l}\text { Foreigner } \\
\text { attitudes }\end{array}$ & $\begin{array}{l}\text { Valuing } \\
\text { diversity }\end{array}$ & \\
\hline Positive contact & $\begin{array}{l}0.10 * * * \\
{[0.06,0.14]}\end{array}$ & $\begin{array}{l}\mathbf{0 . 0 8} \\
{[0.06,0.10]}\end{array}$ & $\begin{array}{l}\mathbf{0 . 0 3} \\
{[0.02,0.04]}\end{array}$ & $\begin{array}{l}0.21 * * * \\
{[0.17,0.26]}\end{array}$ \\
\hline Negative contact & $\begin{array}{l}-0.01 \\
{[-0.04,0.03]}\end{array}$ & $\begin{array}{l}\mathbf{- 0 . 0 7} \\
{[-0.08,-0.05]}\end{array}$ & $\begin{array}{l}-\mathbf{- 0 . 0 1} \\
{[-0.02,-0.00]}\end{array}$ & $\begin{array}{l}-0.08 * * * \\
{[-0.12,-0.04]}\end{array}$ \\
\hline
\end{tabular}

Notes Values in square brackets indicate the $95 \%$ confidence intervals based on 20,000 Monte Carlo simulations. Indirect effects with confidence intervals that do not cross 0 are bolded.

$\dagger p<.1, * p<.05, * * p<.01, * * * p<.001$ 
Figures

Figure 1 . Cross-lagged panel model connecting contact and valuing diversity

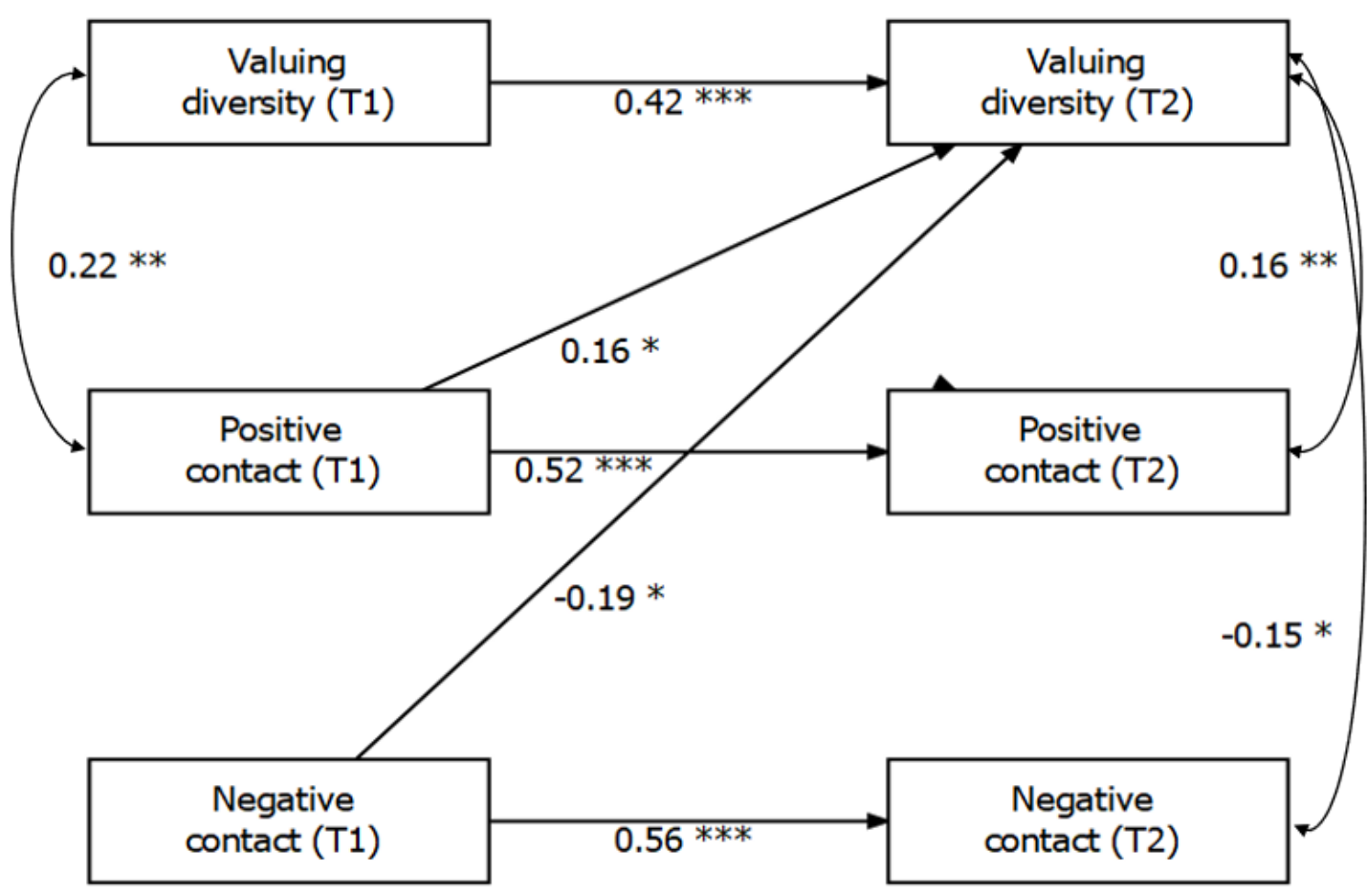

Notes:

Standardized coefficients; paths with $p$-values above .1 are not shown for simplicity

$* \mathrm{p}<.05, * * \mathrm{p}<.01, * * * \mathrm{p}<.001$ 
Figure $2 a$. Mediation models for affective outcomes

\section{Positive contact ...}

\section{Negative contact ...}
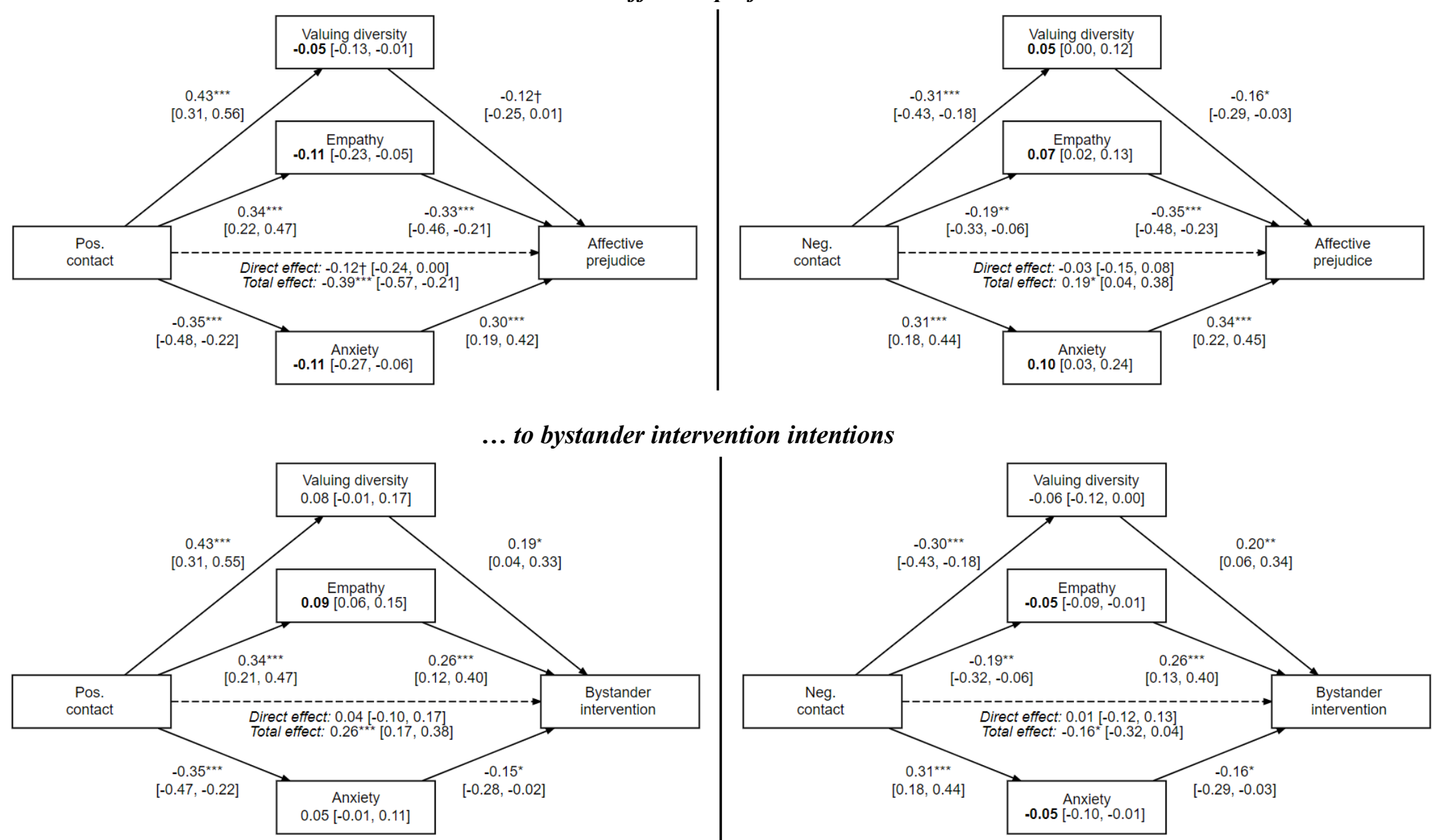

Note: Standardized coefficients, estimated with full-information maximum likelihood. 95\% confidence intervals for indirect effects are based on bias-corrected bootstraps with 5,000 resamples. Indirect effects are shown within the mediator boxes, they are bolded when confidence intervals do not cross 0 .

$\uparrow \mathrm{p}<.1, * \mathrm{p}<.05, * * \mathrm{p}<.01, * * * \mathrm{p}<.001$ 
Figure $2 a$. Mediation models for cognitive outcomes

\section{Positive contact ...}

\section{Negative contact ...}
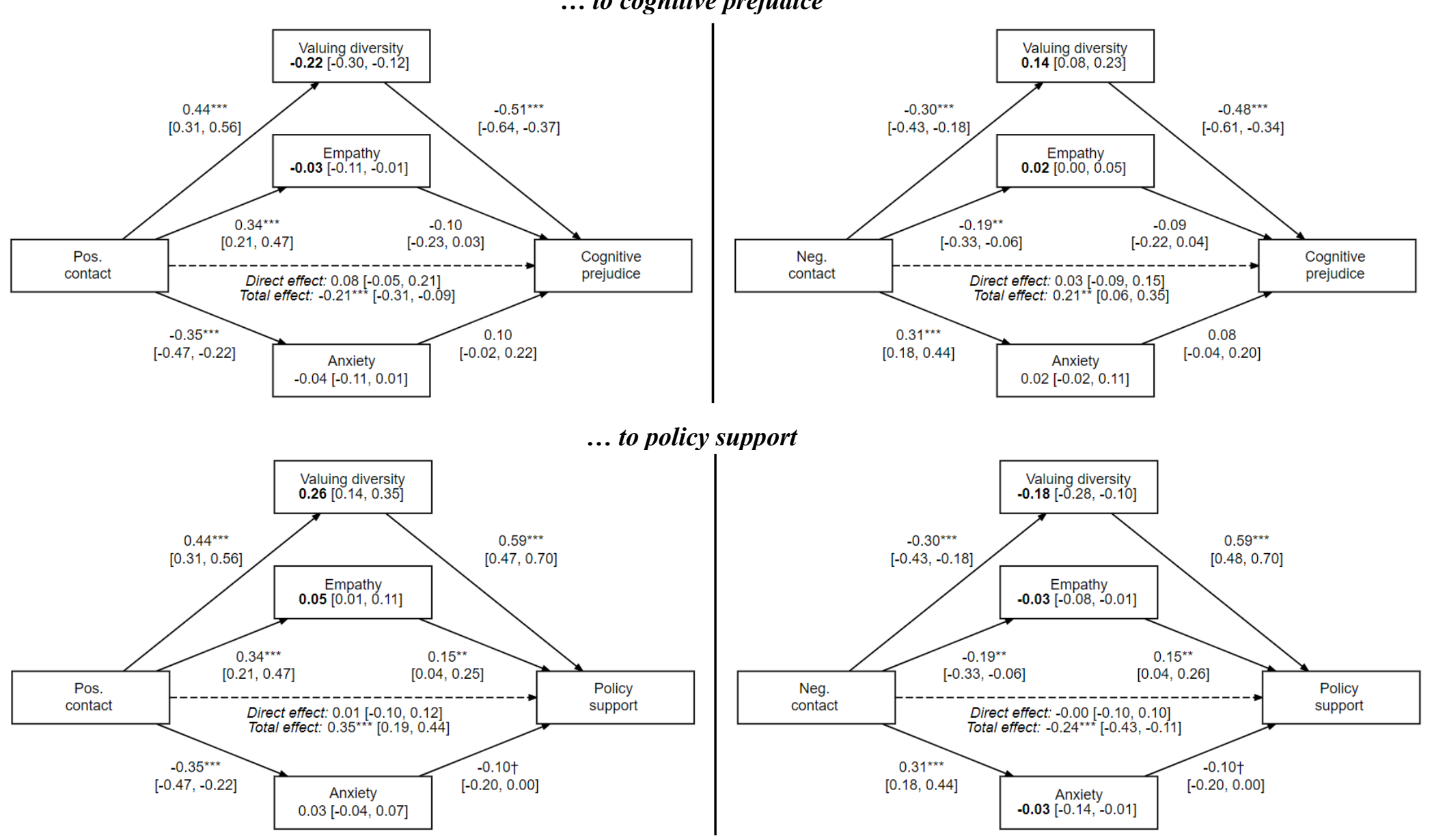

Note: Standardized coefficients, estimated with full-information maximum likelihood. 95\% confidence intervals for indirect effects are based on bias-corrected bootstraps with 5,000 resamples. Indirect effects are shown within the mediator boxes, they are bolded when confidence intervals do not cross 0 .

$\dagger \mathrm{p}<.1, * \mathrm{p}<.05, * * \mathrm{p}<.01, * * * \mathrm{p}<.001$ 
Figure 3. Mediation of the effect of intergroup contact on neighborhood choice

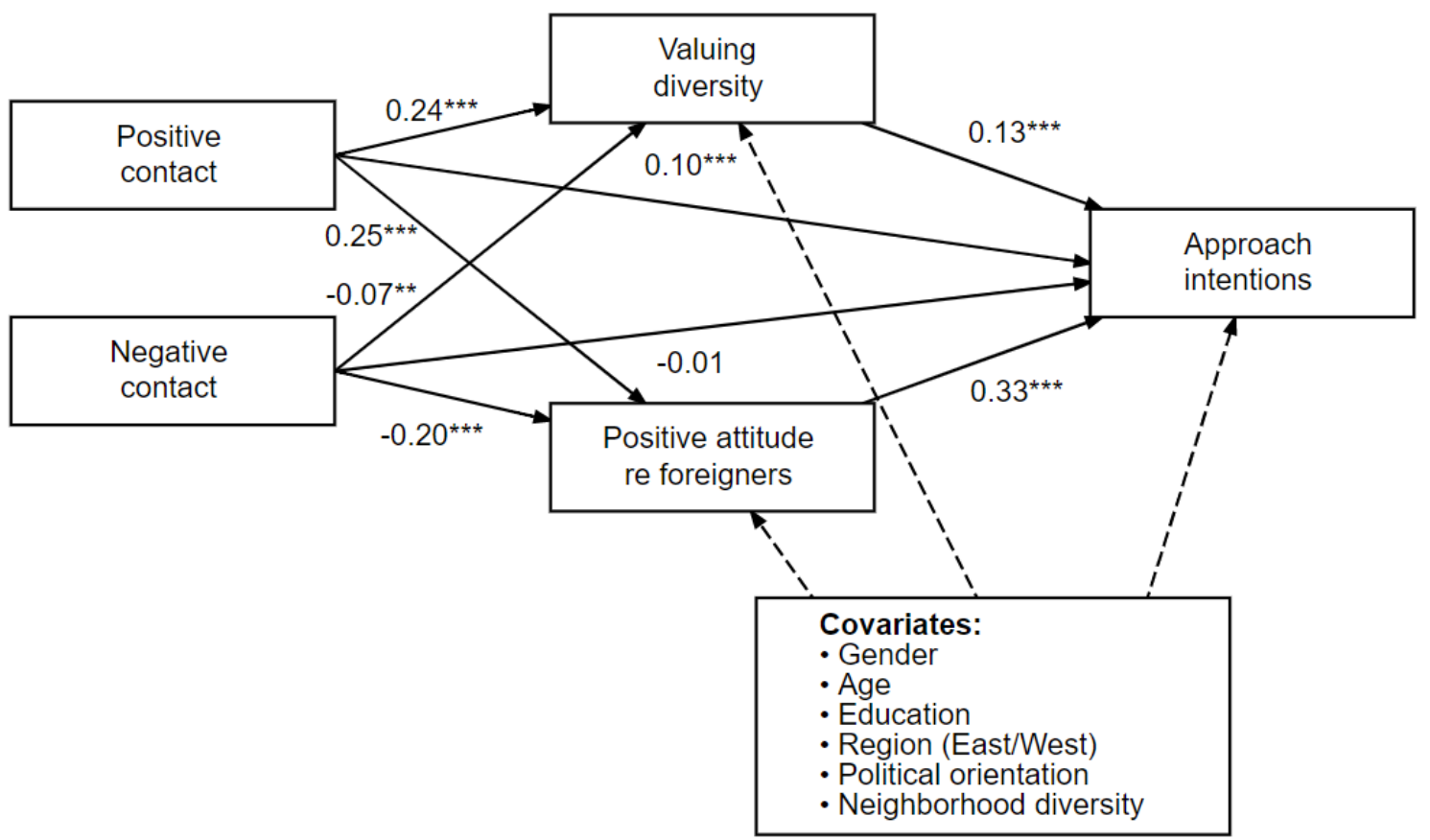

Note: Standardized coefficients, estimated with maximum likelihood on multiply-imputed data. $\dagger \mathrm{p}<.1, * \mathrm{p}<.05, * * \mathrm{p}<.01, * * * \mathrm{p}<.001$ 